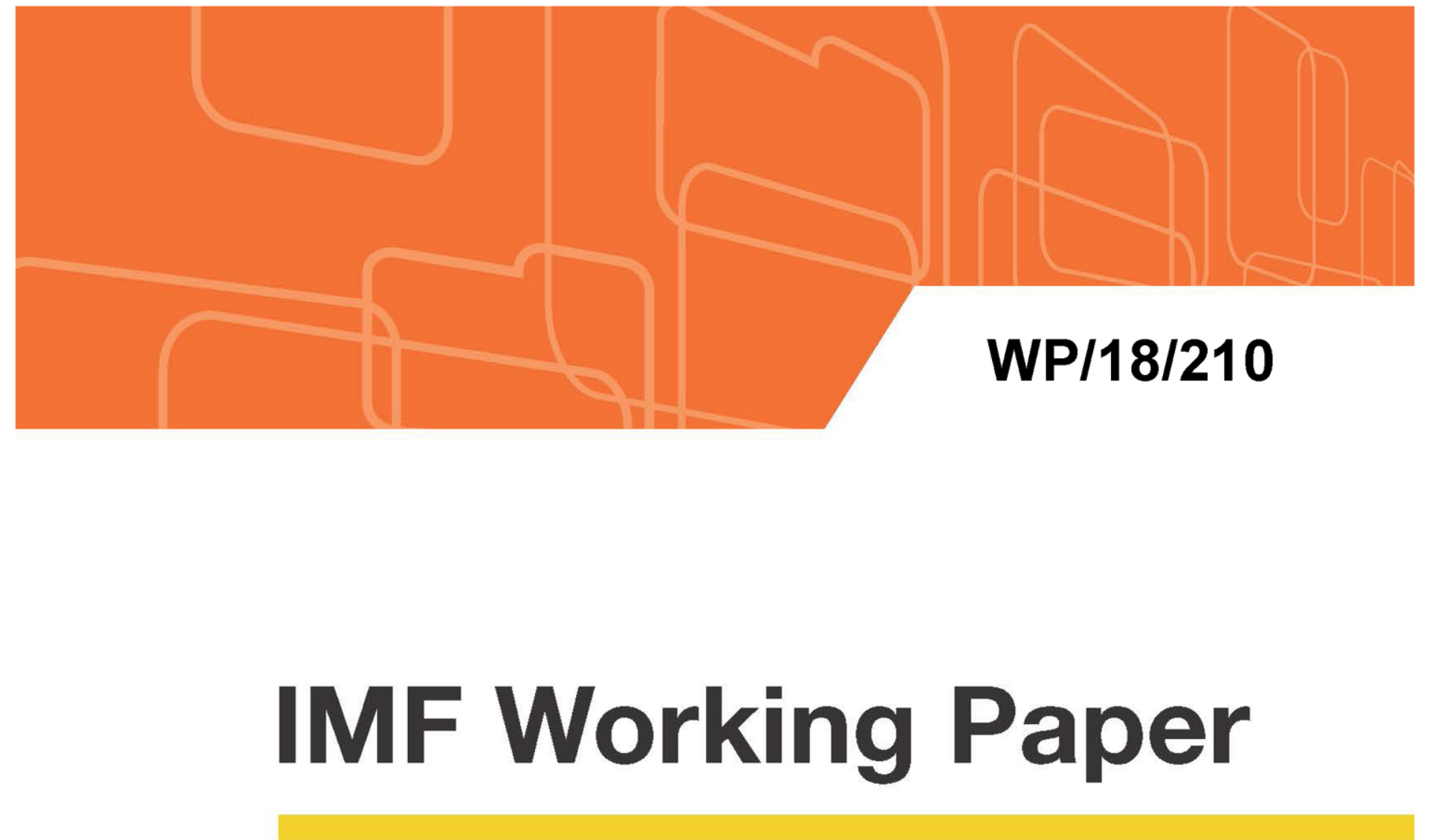

\title{
An Index for Transparency for Inflation-Targeting Central Banks: Application to the Czech National Bank
}

by Rania Al-Mashat, Aleš Buliřr, N. Nergiz Dinçer, Tibor Hlédik, Tomáš Holub, Asya Kostanyan, Douglas Laxton, Armen Nurbekyan, Rafael Portillo, and Hou Wang

IMF Working Papers describe research in progress by the author(s) and are published to elicit comments and to encourage debate. The views expressed in IMF Working Papers are those of the author(s) and do not necessarily represent the views of the IMF, its Executive Board, or IMF management. 


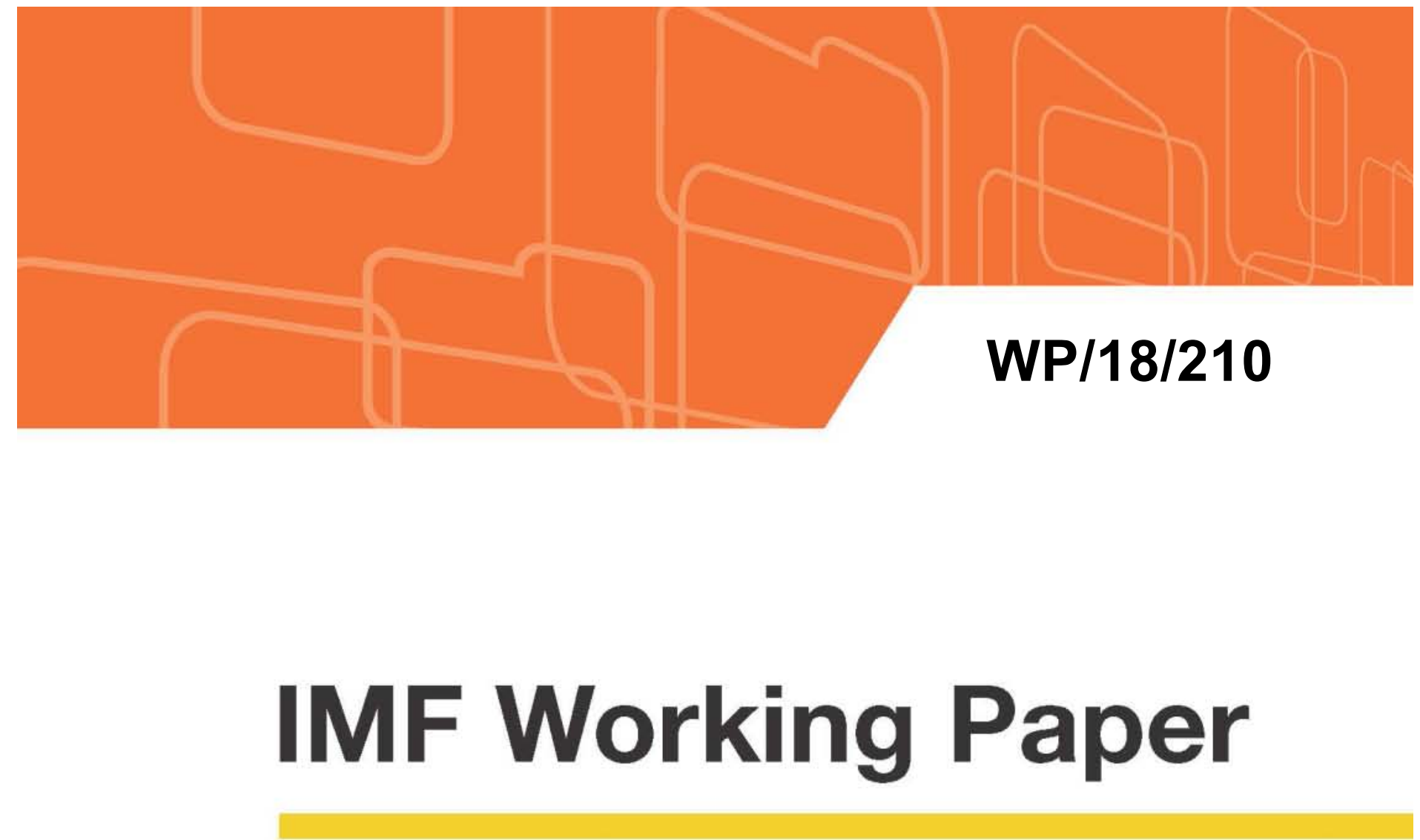

\section{An Index for Transparency for Inflation-Targeting Central Banks: Application to the Czech National Bank}

by Rania Al-Mashat, Aleš Buliř, N. Nergiz Dinçer, Tibor Hlédik, Tomáš Holub, Asya Kostanyan, Douglas Laxton, Armen Nurbekyan, Rafael Portillo, and Hou Wang

IMF Working Papers describe research in progress by the author(s) and are published to elicit comments and to encourage debate. The views expressed in IMF Working Papers are those of the author(s) and do not necessarily represent the views of the IMF, its Executive Board, or IMF management. 


\title{
IMF Working Paper
}

\author{
Research Department
}

\section{An Index for Transparency for Inflation-Targeting Central Banks: Application to the Czech National Bank}

Prepared by Rania Al-Mashat, Aleš Bulír, N. Nergiz Dinçer, Tibor Hlédik, Tomáš Holub, Asya Kostanyan, Douglas Laxton, Armen Nurbekyan, Rafael Portillo, and Hou Wang1

Authorized for distribution by Douglas Laxton

September 2018

\begin{abstract}
IMF Working Papers describe research in progress by the author(s) and are published to elicit comments and to encourage debate. The views expressed in IMF Working Papers are those of the author(s) and do not necessarily represent the views of the IMF, its Executive Board, or IMF management.
\end{abstract}

\begin{abstract}
This paper develops a new central bank transparency index for inflation-targeting central banks (CBT-IT index). It applies the CBT-IT index to the Czech National Bank (CNB), one of the most transparent inflation-targeting central banks. The CNB has invested heavily in developing a Forecasting and Policy Analysis System (FPAS) to implement a full-fledged inflationforecast-targeting (IFT) regime. The components of CBT-IT index include measures of transparency about monetary policy objectives, the FPAS designed to support IFT, and the monetary policymaking process. For the CNB, all three components have shown substantial improvements over time but a few gaps remain. The CNB is currently working on eliminating some of these gaps.
\end{abstract}

JEL Classification Numbers: E0, E4, F0.

Keywords: monetary policy, inflation targeting, transparency, central banks.

Author's E-Mail Address: ABulir@imf.org; nergiz.dincer@tedu.edu.tr; thledik@jvi.org;

Tomas.Holub@cnb.cz; asya.kostanyan@cba.am; DLaxton@imf.org;

armen.nurbekyan@,cba.am; RPortillo@imf.org; HWang2@imf.org

\footnotetext{
${ }^{1}$ Affiliations: Rania Al-Mashat (Ministry of Tourism of Egypt; this work was completed while she was an advisor to the Director of the IMF's Research Department.); Aleš Buliřr, Douglas Laxton, Rafael Portillo, and Hou Wang (International Monetary Fund); Asia Kostanyan and Armen Nurbekyan (Central Bank of Armenia); Tibor Hlédik, (Joint Vienna Institute, formerly Czech National Bank); Tomáš Holub (Czech National Bank). We thank Hamid Faruqee, R. Gaston Gelos, Tommaso Mancini Griffoli, Pau Rabanal, Alasdair Scott, and Juan Francisco Yepez Albornoz for useful discussions and comments on this paper.
} 


\section{Table of Contents}

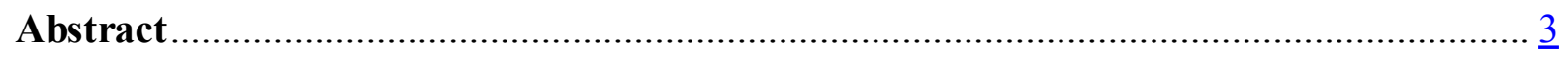

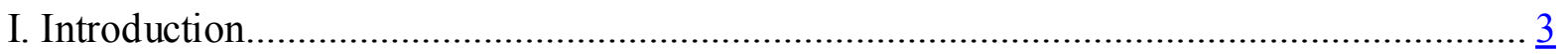

II. Principles of Inflation-Forecast Targeting .............................................................. 4

III. Central Bank Transparency Index: Questions and Motivations ................................... 7

IV. Application of the Central Bank Transparency Index to the Czech National Bank: Evolution over Time ........................................................................................ 16

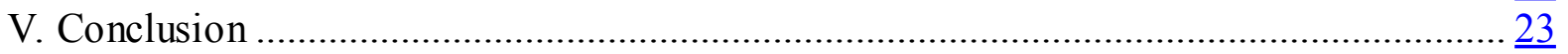

\section{Appendices}

I: Dincer-Eichengreen Central Bank Transparency Questions ...................................... 25

II: CBT-IT Index Questions ................................................................................. $\frac{28}{48}$

III: CBT-IT Index Score for the Czech National Bank in 2017 .................................... 48

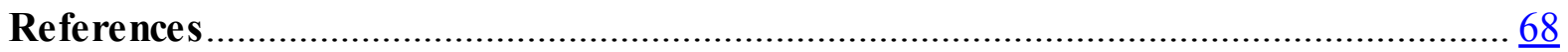

\section{Figures}

1. Monetary Policy Model: IFT Feedback Response and Transmission ...............................

2. CBT-IT Index versus Dincer-Eichengreen Central Bank Transparency Index for the Czech National Bank .................................................................................. 16

3. Evolution of the CBT-IT Index for the Czech National Bank, 1998-2017......................17

4. Evolution of the Three Components of the CBT-IT Index for the Czech National Bank, 1998-2017

\section{Tables}

1. Stages of CNB's Inflation Targeting 


\section{INTRODUCTION}

Transparency improves the effectiveness of monetary policy and provides the basis for accountability. Increased recognition of this principle since the inception of inflation targeting has led central banks to devote considerable resources and effort to improving their transparency. Understanding and documenting this trend towards higher levels of monetary policy transparency requires better measures of central bank transparency. Dincer and Eichengreen (DE, 2014) calculate measures of central bank transparency for more than 120 countries based on 5 broad criteria: political, economic, procedural, policy, and operational (see Appendix I for the questions). Based on these measures of central bank transparency, inflation-forecast-targeting (IFT) central banks are the most transparent central banks in the world, achieving close to a maximum score of 15 . For example, after investing considerable resources on developing a Forecasting and Policy Analysis System (FPAS) to support IFT, the Czech National Bank (CNB) now scores 14.5 out of 15 on the DE index.

The DE index has a few shortcomings. First, it is difficult to compare transparency across different types of monetary regimes, as transparency and communication differ dramatically between central banks pegging the exchange rate or targeting monetary aggregates on the one hand, and those that have adopted inflation targeting and IFT on the other hand. Second, all IFT countries are near the maximum score on the DE index, as the index does not put sufficient emphasis on advanced forms of communications. In other words, it is difficult to differentiate between different IFT countries and between IFT and non-IFT countries. Third, increasing emphasis on financial stability and macroprudential policies after the global financial crisis requires transparent communication of monetary and macroprudential policy interactions. In particular, low levels of transparency about how monetary policy takes into account financial stability considerations pose significant risks for monetary policy credibility.

This paper develops a more ambitious central bank transparency index (CBT-IT index) that focuses only on inflation-targeting central banks, but scrutinizes the practice of those central banks in granular detail. The aim of the CBT-IT index is to establish transparency benchmarks reflecting best practices at the most advanced IFT countries, which would help motivate further transparency improvements. By narrowing our attention to only inflation-targeting central banks, the new index provides a very practical guide to what inflation-targeting central banks could do to improve their transparency in terms of policy objectives, the FPAS, and the policy process.

The application of the index to the CNB shows clearly the improvement in transparency over time. ${ }^{2}$ While the CNB continues to score highly, the new index suggests that there are several ways that transparency could be improved. This includes: (1) providing more information about how the CNB is managing the short-run output-inflation tradeoff; (2) explaining better

\footnotetext{
${ }^{2}$ For a discussion of the history of Inflation Targeting in the Czech Republic see Al-Mashat and others (2018a).
} 
the role of the bands; (3) providing more timely documentation of the core projection model; (4) publishing a complete set of core macroeconomic variables that are included in their baseline forecasts with confidence bands, risk assessments, and decomposition of forecast revisions; (5) explaining the methodology for constructing the forecast confidence bands; (6) publishing more detailed contributions by monetary policy committee (MPC) members in the minutes; and (7) publishing external evaluations of their IFT framework and FPAS at least every 5 years. Several of these initiatives are under consideration by the Board and management of the CNB.

The remainder of this paper is organized in the following way. Section II summarizes the principles of IFT. Section III motivates the choice of questions for the new transparency index and Section IV applies it to the CNB. Section V provides some concluding remarks.

\section{PrinciPles OF Inflation-Forecast TARgEting}

\section{II.1 Defining IFT}

Underpinning the IFT framework is the principle that, given a long-term objective for the rate of inflation, the central bank's own forecast of inflation is an ideal intermediate target (Svensson, 1997). The reason for this is that the forecast would embody all the relevant information available to the central bank, including knowledge of the policymakers' preferences with respect to the tradeoff between deviations of inflation from target and output from potential, and the bank's view of the monetary policy transmission mechanism as summarized in its core macroeconomic forecasting model.

A key aspect of IFT is that the policy interest rate is an endogenous variable that - and this is what distinguishes IFT from IT-lite ${ }^{3}$ - responds to eliminate any deviations of the inflation forecast from the inflation objective. Putting IFT into practice requires an explicit model, because the calculation of even a single endogenous path for the interest rate is too complex a task for casual theorizing. An effective strategy requires the central bank to have a credible model-based framework. Indeed, credibility is at the center of the whole regime. In particular, the more expectations of the public align with the objectives of monetary policy, the lower are the costs of achieving those objectives. This involves transparent communications.

For the purposes of this paper, IFT means that:

- monetary policy is based on a long-run low inflation target, and a medium-term forecast path to this target;

- the forecast path for the short-term interest rate - the policy instrument - is endogenous

\footnotetext{
${ }^{3}$ In the early phases of an IT regime, the central bank may not have had sufficient time to develop an analytical framework that adjusts the expected path of the policy rate to manage the short-run output-inflation tradeoff. We will refer to this form of IT as IT-lite.
} 
within the core projection model, with the rate varying to achieve the long-run inflation target and to eliminate any output gap;

- the forecast is a key input into the MPC's ${ }^{4}$ decision, but only an input-members of the MPC need not agree with the forecast, but use it as an important basis for explaining their own views;

- soon after the policy decision, the associated forecast path for key macroeconomic variables is disclosed, highlighting the path for the inflation rate;

- the rationale for policy actions is explained in greater depth at regular intervals (usually quarterly) in a Monetary Policy Report (MPR - sometimes, less aptly, called an Inflation Report);

- the MPR outlines the endogenous forecast of the short-term interest rate, either with a qualitative description, or with a numerical forecast path;

- the central bank emphasizes the risks to its assessments, verbally, and with confidence bands for those key variables for which numerical forecasts are published.

The history of IT and the transition from IT-lite to IFT and then to full-fledged IFT provides a line of transparency, or accountability. Using the CNB as an example (Table 1), milestones along the way have been:

- Announcement of targets with a multi-year horizon - clarity of target (IT-lite);

- Precision on the policy interest rate setting - clarity of instrument (IT-lite);

- Transparent communications on policy implementation (IT-lite);

- Publication of the inflation forecast constructed under the assumption of an endogenous interest rate - clarity of the intermediate target (IFT);

- Publication of a conditional numerical forecast path of the endogenous interest rateclarity of how the central bank is managing the short-run output-inflation trade-off (full-fledged IFT).

\section{Table 1. Stages of CNB's Inflation Targeting}

\begin{tabular}{|c|c|c|}
\hline IT-Late & $\begin{array}{c}\text { Inflation-Forecast } \\
\text { Targeting }\end{array}$ & $\begin{array}{c}\text { Full-Fledged } \\
\text { Inflation-Forecast Targeting }\end{array}$ \\
\hline 1998-2001 & $2002-2007$ & $2008-2013$ \\
\hline
\end{tabular}

Source: Authors' construction.

Because of the increased opportunities to learn from others, it has become possible for newer entrants of IT to leapfrog the pack, and in some respects, jump straight to the frontiers to become a full-fledged IFT central bank, as the Bank of Israel and the Norges Bank have shown

\footnotetext{
${ }^{4}$ We use the term MPC for the key policymaking body in all central banks, regardless of the formal name.
} 
(see, for example, Naudon and Pérez, 2017). The U.S. Federal Reserve is one of the best recent examples of an IFT central bank given the strong emphasis on its dual mandate (specifying full employment as well as low inflation) and the Fed's 2012 announcement of a 2 percent long-term inflation objective. ${ }^{5}$

Under IFT, the central bank communicates to the public not just a possible path for the future policy rate, but also a sense of how this path might change in response to a variety of developments, and a rationale for policy actions. Thus, there is an aspect of improved accountability, as well as improved policy effectiveness, with an IFT strategy.

\section{II.2 The Transmission Mechanism}

Macroeconomic models traditionally emphasize two main channels for the influence of monetary policy on the economy: the domestic channel, via the short-term market interest rate, which is controlled quite closely by the central bank; and the external channel, via the exchange rate.

\section{Figure 1. Monetary Policy Model: IFT Feedback Response and Transmission}

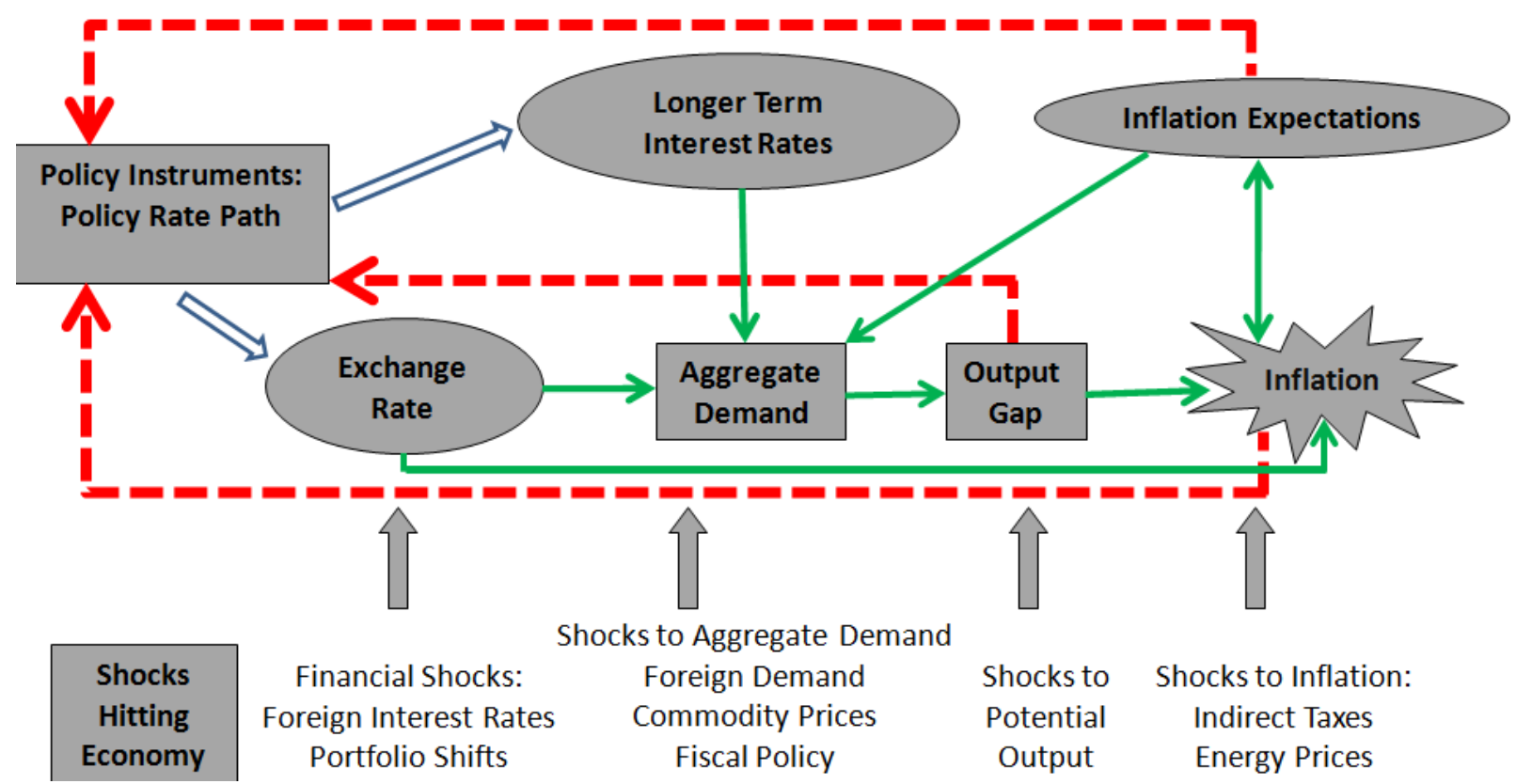

Source: Clinton and others (2015).

The difference between IFT with an endogenous, forward-looking policy reaction function, and some other approaches to IT, for example use of an exogenous forecast interest rate path

${ }^{5}$ For a discussion of the U.S. case see Alichi and others (2015b), Al-Mashat and others (2018) and Adrian, Laxton and Obstfeld(2018). 
(including a path derived from market forward rates), is that the latter do not have explicit feedback from the expected future inflation rate to the policy instrument. If Figure 1 were modified to represent an exogenous interest rate path, the red dashed feedback arrows would be erased.

Modern monetary policy models emphasize the role of expectations in the transmission mechanism. Policy affects what interest rates businesses and households face through the impact of the policy rates expected in the future-i.e., the whole yield curve - rather than the current policy rate itself. This is reflected in the rectangle for the "Policy Rate Path" - the whole path expected for the medium term, not just the current setting, is what counts. Likewise, the impact of a given policy action is also a function of the expected duration of the action.

Recognition of the crucial role of expectations has been reflected in the increased attention that central banks have given to transparent communications about monetary policy. When monetary policy is constrained by the effective lower bound (ELB), the ability of a credible central bank to affect expectations in a helpful direction provides a means for an effective antideflation policy.

\section{CENTRAL BANK TransParency Index: QUeSTIONS AND Motivations}

The CBT-IT index covers three broad aspects, consistent with the theoretical underpinnings of an IFT framework, namely: Transparency about Objectives (4 questions), Transparency about the Forecasting and Policy Analysis System (9 questions), and Transparency about Policy Process (7 questions). Appendix II contains the questions and the scoring system.

\section{III.1 Transparency about Objectives (Question A1-A4)}

The section "Transparency about Objectives" examines the transparency of the central bank along four dimensions: statement of its objectives; clear communication of those objectives; communication of performance of the central bank in terms of managing the short-run outputinflation tradeoff; the role of financial stability in monetary policy communication.

The primary role of monetary policy is to provide a nominal anchor for the economy. In the case of IFT central banks, the inflation target and its ability to pin down long-run inflation expectations are the nominal anchor. In practice, however, central banks are not "inflation nutters," and it is neither feasible nor desirable to target inflation on a period-by-period basis. Central banks have other objectives, such as output and unemployment, which are consistent with providing an anchor for inflation and inflation expectations in the long term but give rise to various short-run tradeoffs. IFT is based on the principle that, given a long-term objective for the rate of inflation, the central bank's own forecast of inflation is an ideal intermediate target (Svensson, 1997), which allows the central bank to conduct monetary policy with the 
desired tradeoff between deviations of inflation from target and deviations of output from potential.

The credibility of the long-run inflation target underpins IFT. Everything pivots around the anchor provided by the firm expectation of the public that monetary policy will in the long run keep inflation stable and near the target rate. To achieve this, the central bank should be explicit that inflation is the primary objective and that it is in effect managing the short-run outputinflation tradeoff. Therefore, the central bank does not score on the CBT-IT index if there are multiple objectives without such prioritization.

Ambiguity surrounding the inflation target itself weakens the central bank's transparency. Based on the theoretical foundations of IFT, the central bank gets the highest score if it has a well-defined point target. Other definitions, such as "tolerance" or "control" ranges can potentially confuse market participants if they are considered ranges of tolerance or indifference, rather than ranges of uncertainty. Most of the IFT central banks define their operational target in one of the following ways: (1) a point target without a band to be a single quantitative number (e.g., 2 percent); (2) a point target with a band to be a number plus or minus an uncertainty interval (e.g., 2 percent $+/-1$ percentage point); and (3) a tolerance or control range target to be an interval without a single quantitative central number (e.g., 1 percent to 3 percent).

The choice of point target versus range is important to the extent that it affects the interpretation of the chosen arrangement. In most cases, monetary policy should treat movements of inflation above and below the point target or the center of the target range symmetrically (except when the policy interest rate is close to the ELB, where below-target inflation might be more dangerous). Although a point with a band or a range target helps to communicate the uncertainty underlying the policy outcome - that the central bank expects to be inside the band or range most (but not all) of the time, the evidence suggests that they may be less effective than a point target in providing a focal point for inflation expectations over the medium to long term. An important disadvantage of range targeting is that long-term inflation expectations can get stuck at the upper or lower parts of the target range (see Goretti and Laxton, 2005). Indeed, empirical evidence shows that long-term inflation expectations have become better anchored in inflation-targeting countries that have a well-defined point target for inflation and have established a track record achieving an inflation rate that is, on average, close to its long-term target (see Freedman and Laxton, 2009a, b, c).

As a good example of more precise language the Riksbank has recently introduced an uncertainty interval around its point target, using the following language to describe it: "Although the aim is that inflation shall be 2 percent, outcomes will always vary around the target. To illustrate in a simple manner the fact that monetary policy has little ability to steer inflation in detail, the Riksbank uses a variation band in its monetary policy communication with effect from September 2017. A variation band that stretches between 1 and 3 per cent 
captures approximately three-quarters of outcomes for CPIF inflation since mid-1995. The variation band does not affect the formulation of monetary policy. The Riksbank always aims for 2 per cent inflation, regardless of whether inflation is initially inside or outside the variation band." (Riksbank, "The Inflation Target," Riksbank website)

Following the global financial crisis, the extent to which monetary policy can and should contribute to financial stability beyond providing a low, predictable, long-run rate of inflation has been at the center of debate. Transparency of the central bank about its financial stability objectives and tools is critical to avoid public perception that these objectives may undermine confidence in inflation objectives and result in a loss in monetary policy credibility. ${ }^{6} \mathrm{We}$ consider two cases: central banks with a formal mandate for financial stability and central banks without direct responsibilities for financial stability. Central banks with a formal financial stability mandate should have the authority to use macroprudential tools to tame or prevent financial imbalances. Transparency means that central banks should make clear how these tools will be adjusted to achieve financial stability objectives without jeopardizing monetary policy objectives. If the central bank doesn't have the authority to deploy macroprudential tools or doesn't communicate the framework, which it uses to adjust these tools, it scores low. In cases where the central bank does not have a financial stability responsibility, it should be explicit that it still cares about financial conditions because such information is critical for efficiently managing the short-run output-inflation tradeoff, but does not go beyond this monetary policy perspective (Adrian and others, 2018). Both approaches allow the central bank to get a full score on the CBT-IT index as we don't take a stand on the "right" institutional design, but focus on the degree of transparency given the institutional design. It is worth noting that the communication challenge is immense when monetary policy "leans" to subdue sustained credit growth or asset price movements, the two main indicators of potential macro-financial instability.

The last pillar of central bank transparency about objectives is the communication of the achievement of policy objectives. In particular, central banks should provide clear communications about how well they have been managing the short-run output-inflation tradeoff. One approach is to calculate the historical value of a quadratic loss function that penalizes inflation deviations from its target, output deviations from potential, and changes in the policy interest rate. The loss function approach is consistent with the theoretical foundations of IFT and provides easily understandable metrics to assess the management of the short-run output-inflation tradeoff.

\footnotetext{
${ }^{6}$ For models designed for macroprudential policy analysis see Benes, Kumhof and Laxton (2014a,b) and Benes, Laxton, and Mongardini (2016).
} 


\section{III.2 Transparency about the Forecasting and Policy Analysis System (Question B1-B9)}

Putting IFT into practice requires a Forecasting and Policy Analysis System (FPAS), in which the forecast is organized around a core quarterly projection model. The FPAS is the organizational framework that provides the regular flow of macroeconomic information to policymakers for their decisions on the policy instrument path (e.g., the policy interest rate). Main elements of the FPAS are:

- a monetary policy model containing a policy reaction function or a loss function under which the short-term interest rate responds endogenously to return inflation to the longterm target;

- a system of communication between policymakers and model builders, to ensure that the model structure broadly captures the key features of the transmission mechanism as viewed by the policymakers;

- a system of communication between policymakers and the forecasters before and during forecast production, to develop a consensus set of assumptions for a baseline forecast, and for alternative scenarios.

The system provides the following key inputs for each decision making:

- a baseline forecast-including an endogenous forecast path for the short-term interest rate;

- risk assessments surrounding the baseline forecast;

- alternative scenarios to the baseline forecast—each with an endogenous interest rate path.

Each FPAS forecast-baseline forecast and alternative scenarios-contains: (a) an inflation rate projection that shows a return to the long-term target within a medium-term horizon; and (b) a consistent forecast for relevant endogenous macroeconomic variables. Publication of the forecast is thus an instrument that helps policy achieve its objectives. Making effective the strategy that emerges from the FPAS requires credibility: the better the expectations of the public align with the objectives of monetary policy, the lower are the costs of achieving those objectives. This involves transparent communications, elements of which are covered in 9 distinct questions of the CBT-IT index that address elements of a robust FPAS process.

At the outset, availing the historical and key forecast databases used in the monetary policy making within the FPAS is the first element of transparency. The central bank gets a full score in the CBT-IT index if the data for the time series used for producing forecasts in the monetary policy reports are available, particularly capacity utilization (preferably the output gap), inflation, inflation expectations, wages, unemployment, and GDP. The central bank scores less 
if fewer time series are available. Moreover, for increased transparency the central bank should share both historical and key forecast databases. ${ }^{7}$

The core monetary policy model is a key input in the FPAS as it reflects the central bank's view of the economy and the monetary policy transmission channel. Moreover, it demonstrates the short-run output-inflation tradeoff and its medium-term implications for the policy instrument as implied by either the monetary policy reaction function and/or the loss function. On the CBT-IT index, the central bank receives a full score if the core model is transparently documented and the replication code (including judgmental assumptions) made available to the public. In addition, as the structure of the economy is likely to evolve over time, the model documentation should be updated at least once every 5 years. The Riksbank provides a good example here as the forecasting model, Ramses II, is published on the website along with the model codes.

Within the monetary policy model, the interest rate responses are derived from a policy reaction function or from minimizing a loss function. The policy reaction function and the loss function capture the preferences of the policymakers relative to the short-run tradeoffs between the variability of inflation, output, and the interest rate. In practice, monetary policy involves informed judgment that goes beyond the technical outcomes produced by the reaction function or loss function within the core projection model. Therefore, in line with what we believe to be the frontiers of IFT transparency, the central bank scores high on the CBT-IT index when it publishes either the reaction function or loss function (with the coefficients) and communicates the judgment that has been involved in the forecast. ${ }^{8}$

The model or models used by central banks in conducting policy under IFT logically should incorporate an endogenous interest rate. A model in which the interest rate is exogenous has no nominal anchor-the inflation rate should drift indeterminately following disturbances. Under IT, the nominal anchor for the economy is provided by the expectation that the rate of inflation will converge to the announced long-run objective. This implies an expectation that in response to any shock, monetary policy will react in such a way as to return inflation to the long-run target. For the policy to be logically consistent, the interest rate must adjust to the requirements of the target.

\footnotetext{
${ }^{7}$ Although we do not score explicitly the publication of high frequency databases and statistical models for nowcasting, the central bank should nevertheless document them and explain how those data movements and statistical models help impose judgment on the core forecasting model.

${ }^{8}$ While the reaction functions may provide reasonable results in normal times, they have difficulty in abnormal times. When policy interest rates are at or very near the effective lower bound, the quadratic loss-function approach appears to produce better results because its response to disinflationary conditions involves an extended commitment to keep the rate at the floor (Obstfeld and others, 2016). The desire for continuity in policy would argue that more attention should therefore be paid to the loss-minimization approach, in both normal and abnormal circumstances. Nonetheless, this does not imply that information from the reaction function should be ignored. It can serve as a crosscheck to the results from the loss-minimization approach, especially when there is concern that the model specification may be less than satisfactory.
} 
Many central banks incorporate this principle into their forecasting models and thus produce an endogenous path for the interest rate. ${ }^{9}$ However, most of these institutions have not published the path. The principal worry about publishing the explicit path for projected interest rates has been that people might misinterpret it as a commitment, regardless of changing developments, or underestimate the central bank's perception of the uncertainties that lie ahead. This concern, however, has been dealt with, first, by publishing confidence bands around the endogenous interest rate path, and second by emphasizing the conditional nature of the projection. ${ }^{10}$ Indeed, one of the most important messages that an IFT central bank should communicate to the public - whether it publishes an explicit rate path or not - is that the forecast is conditional upon information available at the time of writing and will almost certainly change as new information (and new interpretations) become available. Associated with each simulation would be confidence bands for the key variables, reflecting the normal range of random factors that may affect the forecast. Hence, publishing the confidence bands enhances the transparency of the central bank's forecast and the associated monetary policy decisions, and increases the effectiveness of monetary policy transmission. At the same time, the confidence bands illustrate the degree of uncertainty and the conditional nature of the published path.

Against this background, and to be at the frontiers of transparency, the CBT-IT index gives the full score to central banks that publish the fan charts for all macroeconomic variables (inflation, GDP growth, the endogenous interest rate path, the output gap, and the exchange rate). Moreover, publishing the underlying methodology of constructing the fan charts and making it easily accessible to the public provides an additional score on the CBT-IT index. Understanding the underlying methodology of the construction of the fan charts increases the value of the information for the users. In particular, the central bank should explain if the fan charts reflect (i) monetary policy reaction to shocks using model-based stochastic simulations, (ii) historical experience (past forecast errors), (iii) judgment (e.g., magnitude of structural shocks versus measurement errors), and (iv) other constraints (e.g., effective lower bound).

As every forecast is fraught with risk it is important that the most relevant risks weighing on policymakers' minds be communicated to financial markets and the public. The simulation of alternative scenarios becomes a helpful technique to illustrate a couple of potential risks in the baseline forecast. Unlike the fan charts, alternative scenarios present consistent stories, which reflect other possibilities that the central bank has been considering. They illustrate the uncertainties implied by shocks which MPC members judge to be relevant, and which might go beyond the normal range of random variability. We believe that the frontiers of IFT require the central bank to indicate how the policy rate might respond should any of the posited shocks

\footnotetext{
${ }^{9}$ The principle is sometimes referred to as the Taylor principle.

${ }^{10}$ For examples of papers that construct model-consistent confidence bands with the effective-lower bound for the policy rate see Clinton and others (2010) and Alichi and others (2015b).
} 
eventuate - a concrete and effective method of communicating to financial market participants the nature of the perceived risks, and of the systematic policy reaction function. The CBT-IT index gives a full score to a central bank that clearly communicates the full-fledged alternative scenarios considered during the forecast, while penalizing those banks that treat the scenarios as sensitivity tests, where only one variable is changing and the rest is kept constant.

Central banks have generally been quite cautious in moving to a published interest rate forecast. In most cases the practice followed many years after the adoption of IT - the shortest gap was 4 years at the Norges Bank. To reach the point where publishing an endogenous interest rate path became a feasible option, the central banks first had to build models with endogenous policy rates, and then use them as the basic forecasting tool. Policymakers then had to become confident in the process and output of their FPAS before they were ready to publish the explicit path and confidence bands for the interest rate forecast.

Markets on the other hand have adapted surprisingly quickly. As for the perceived communications risks, the experience in New Zealand since June 1997, Norway since November 2005, Sweden since February 2007, Israel since July 2007, and the Czech Republic since February 2008 suggests that concerns have been overblown. In particular, financial market participants did not find it difficult to accept the idea of the conditionality of a projected interest rate path. For example, in the case of Sweden, whereas Riksbank officials stated at the outset that they expected that it would take some time for people to learn and accept the system, in practice this adjustment phase seems to have been easier than anticipated. Clinton and others (2017) document the experience of the CNB with respect to its publication of the interest rate path and conclude that the overall experience has been positive.

Communicating the underlying causes of forecast revisions is another critical component of IFT. The forecast changes over time, because of new information, and of changes in its interpretation of economic developments. Central banks are expected to explain the types of shocks or underlying assumptions behind the forecast revisions. According to the CBT-IT index, the central bank scores the highest when it publishes the forecast revisions of the full set of both historical and projected macroeconomic variables: inflation, GDP growth, the endogenous interest rate path, the output gap, and the exchange rate.

Finally, it is well-known that measures of financial conditions can significantly improve forecasting performance of models. For example, Carabenciov and others (2013) and Benes and others (2010) show that the information in the Fed's senior loan officer survey substantially improved forecasts of the output gap, inflation and the fed funds rate. Adrian and others (2018) construct more sophisticated measures of financial conditions and show how they can be used to help forecast output and the desired path of the policy rate. Given the attention that has been given to adding financial restrictions to structural models, the CBT-IT index includes a question that tracks how much attention is given to measures of financial conditions in the monetary policy reports. 


\section{III.3 Transparency about Policy Process (Question C1-C7)}

In an IFT regime, the release of the central bank's forecast for output and inflation is a key news item for the business and financial media. The forecast changes over time, because of new information, and of changes in its interpretation of economic developments. In turn, the central bank's evolving views on the economic outlook are a central element in the analyses and discussions of academics, financial market participants, and commentators in the business media (including the experts that the media rely upon for comment), who are the main conduit of information to the public.

The central bank's message must be tailored for multiple audiences. These include the public at large, financial markets, the media, parliamentary bodies, and the government. The normal convention today, after an MPC decision, is for the central bank to announce immediately the policy interest rate setting applicable until the next meeting. Soon afterwards, press releases provide a brief rationale. To achieve the full score on the CBT-IT index, the central bank following every policy meeting, and at pre-announced dates and times, should hold a press conference. Moreover, the press conference as well as the questions and answers (Q\&A) sessions should be webcasted and made available on the central bank's website. The presentations and Q\&A sessions should be in English, as English is widely used for finance business in the world.

Similarly, organizing regular meetings with market analysts is another important communication tool. Clearly explaining the assumptions underlying the policy decisions and the risks that surround the baseline forecast strengthens the central bank's policy message and hence manages market expectations more effectively. The CBT-IT index gives the highest score when the central bank presents its regular forecast updates to journalists, analysts, and market participants, and when the audience is given the opportunity to ask questions and provide comments. As in the previous question, presentations of the meetings should also be available in English.

Practices towards the release of MPC minutes vary, with respect to level of detail, and time delay. To be at the frontiers of transparency, the central bank should publish detailed minutes with the voting outcomes on the main policy instrument. Moreover, the contributions of the individual MPC members should be clearly attributed. For example, the Riksbank publishes a separate document ("Monetary policy minutes"), which contains a full account of the discussions and the contribution of each MPC member during the meeting. Providing a timely description of the range of views among members conveys the central tendency of opinion, and, just as important, the range of dispersion provides an indicator of the size of the uncertainties confronting monetary policy. This provides financial market participants a better understanding of developments that will be central to the bank's thinking with respect to interest rate decisions over the period ahead, and how it might react to new information in the areas where it expresses most uncertainty. 
With respect to the institutional modalities of the forecast, communications may be simpler when the forecast is presented as a staff input. The alternative approach, in which the MPC takes ownership of the forecast, may be more difficult at a central bank where decisions are made by vote, rather than by consensus (or by the Governor alone ${ }^{11}$ ). Voting members may have divergent views that could not be represented in a single forecast. Where there is no consensus, a central bank with 7 voting members may have to publish up to 7 projections in the MPR. And how would all this be accommodated in the write-up explaining policy? Such an approach would likely be inefficient internally and confusing externally. Instead, a published staff forecast would be a point of reference, with respect to which individual members could compare their own views. The model-based staff forecast presented to the MPC meetings provides a coherent, and broadly agreed macroeconomic narrative, linking the current and forecast settings of the interest rate instrument to the inflation and output objectives. The model-based forecast should not be considered a mechanical exercise, rather an input during the policymaking process, but not the only one. Against this background, the central bank gets the full score within the CBT-IT index if the role of the staff and the policymakers in the decision-making process are defined clearly. The CNB provides one of the best examples among IFT central banks. In the Foreword of the Inflation Report, the CNB states clearly that:

"The forecast is the key, but not the only, input to our monetary policy decision-making. Unless the economic situation requires an extraordinary monetary policy meeting, the Bank Board meets eight times a year to discuss monetary policy issues. At four of the meetings (in February, May, August and November) we discuss a new forecast, while at the other four (in March, June, September and December) we discuss the risks and uncertainties of the most recent forecast in the light of newly available information on domestic and foreign economic developments. Due to the arrival of new information since the forecast was drawn up and to the possibility of the Bank Board members assessing its risks differently, the decision we adopt may not fully correspond to the message of the forecast prepared by our experts." (CNB Inflation Report, IV/2017).

Finally, IFT central banks that want to push the frontiers of transparency would review and publish the forecast performance at least once a year to get a full CBT-IT score. In addition, if they allow an external and independent evaluation of the policy framework and the FPAS every five years, they secure another full score on the CBT-IT index.

\footnotetext{
${ }^{11}$ In some countries, the Governor of the central bank, rather than a committee, is accountable for the conduct of monetary policy, e.g., New Zealand. The Governor may well set the main themes of the forecast. She or he must therefore defend it, in justifying her or his policy actions.
} 


\section{Application of the Central Bank Transparency IndeX to THE CzeCh NATIONAL BANK: EVOLUTION OVER TIME}

According to the Dincer and Eichengreen (2014) central bank transparency index, the CNB has scored almost a perfect score of 14.5 (out of 15) since 2011, making it one of the most transparent central banks in the world. Our CBT-IT index also scores the CNB at high levels, but suggests that there are a few areas where the CNB could further improve transparency (Figure 2). This section reports the historical CBT-IT scores since the CNB adopted IT in 1998 and then identifies the areas where transparency could be improved in the future. It should be stated up front that the CNB already has plans to improve monetary policy transparency in some of the areas discussed below. Appendix III provides an explanation of the 2017 scores, recommendations for the $\mathrm{CNB}$, as well as CNB's comments for some questions.

\section{Figure 2. CBT-IT Index versus Dincer-Eichengreen Central Bank Transparency Index for the Czech National Bank (in percent of each index's maximum score)}

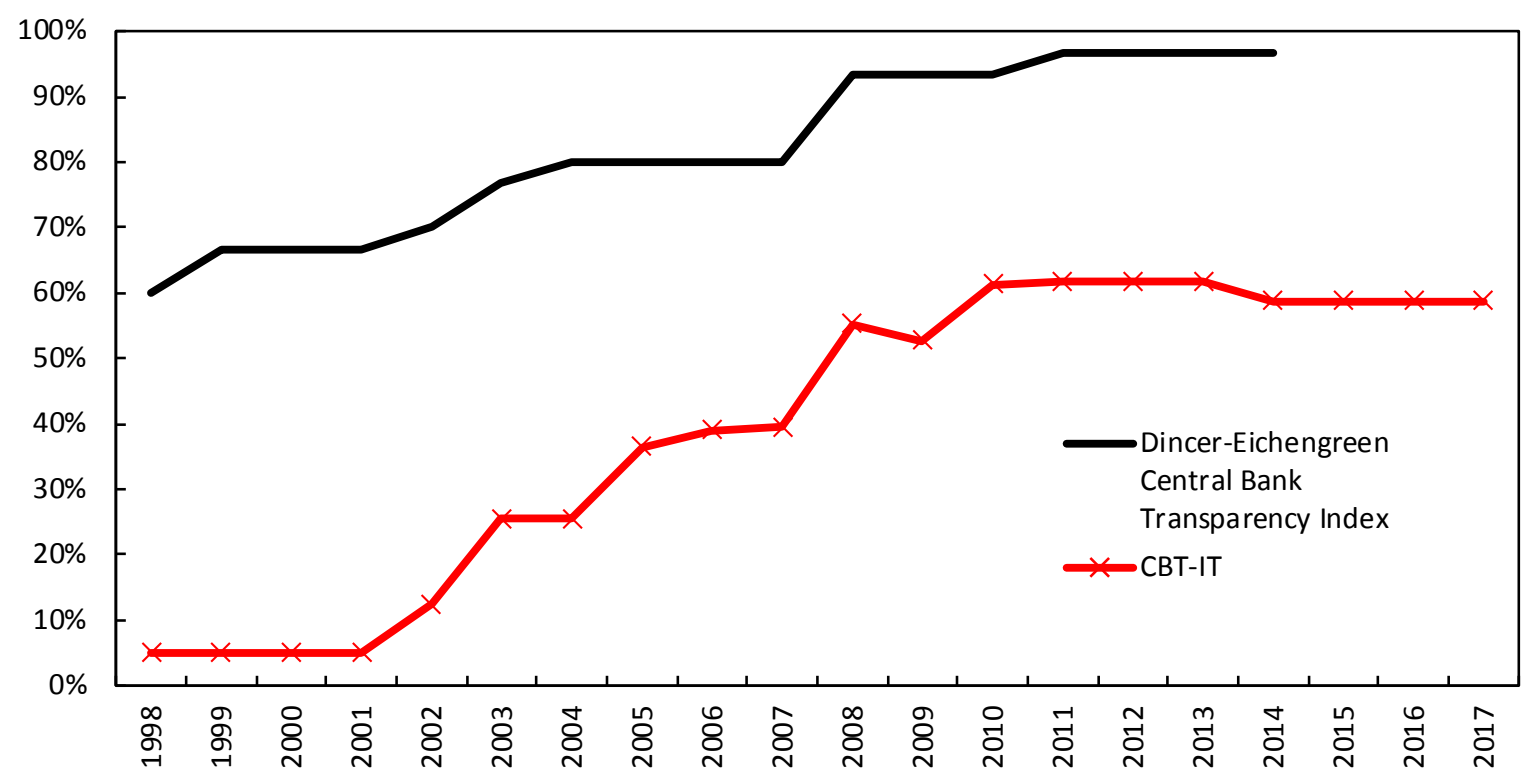

Source: Dincer and Eichengreen (2014); authors' calculation.

As was the case with many of the countries that adopted IT in the 1990s, there was very little preparation before actual adoption. In 1997, the Czech Republic was hit by a currency crisis. The CNB was unable to maintain a pegged exchange rate and was effectively thrown into a floating exchange rate regime. The CNB decided to adopt a simple, lite version of IT (referred to at the CNB as an IT strategy), and recognized afterwards that it would take substantial effort and time to develop a Forecasting and Policy Analysis System (FPAS) to support an IFT regime. Not surprisingly, the initial version of IT in 1998 was associated with very low levels of monetary policy transparency. 


\section{The early years before the FPAS and IFT (1998-2001)}

Figure 3 reports the aggregate quantitative magnitude of the CBT-IT index and Figure 4 shows the score for each of the three components. The index is equal to 1 out of 20 between 1998 and 2001. This low score reflects the fact that the CNB revealed very little about its monetary policy objectives and the policy process. At the same time, they receive zero score for transparency about the FPAS, as the CNB did not have an FPAS that was up to the task to support IFT. Management and staff at the CNB were aware of the issues associated with not having an adequate framework, and started investing heavily through IMF technical assistance and direct contacts with other central banks to get help developing an FPAS to support its new regime. The development of the FPAS took place over a 3-year time frame and was implemented in 2002 and later documented in an FPAS book in 2003 (Coats, Laxton and Rose, 2003).

Figure 3. Evolution of the CBT-IT Index for the Czech National Bank, 1998-2017

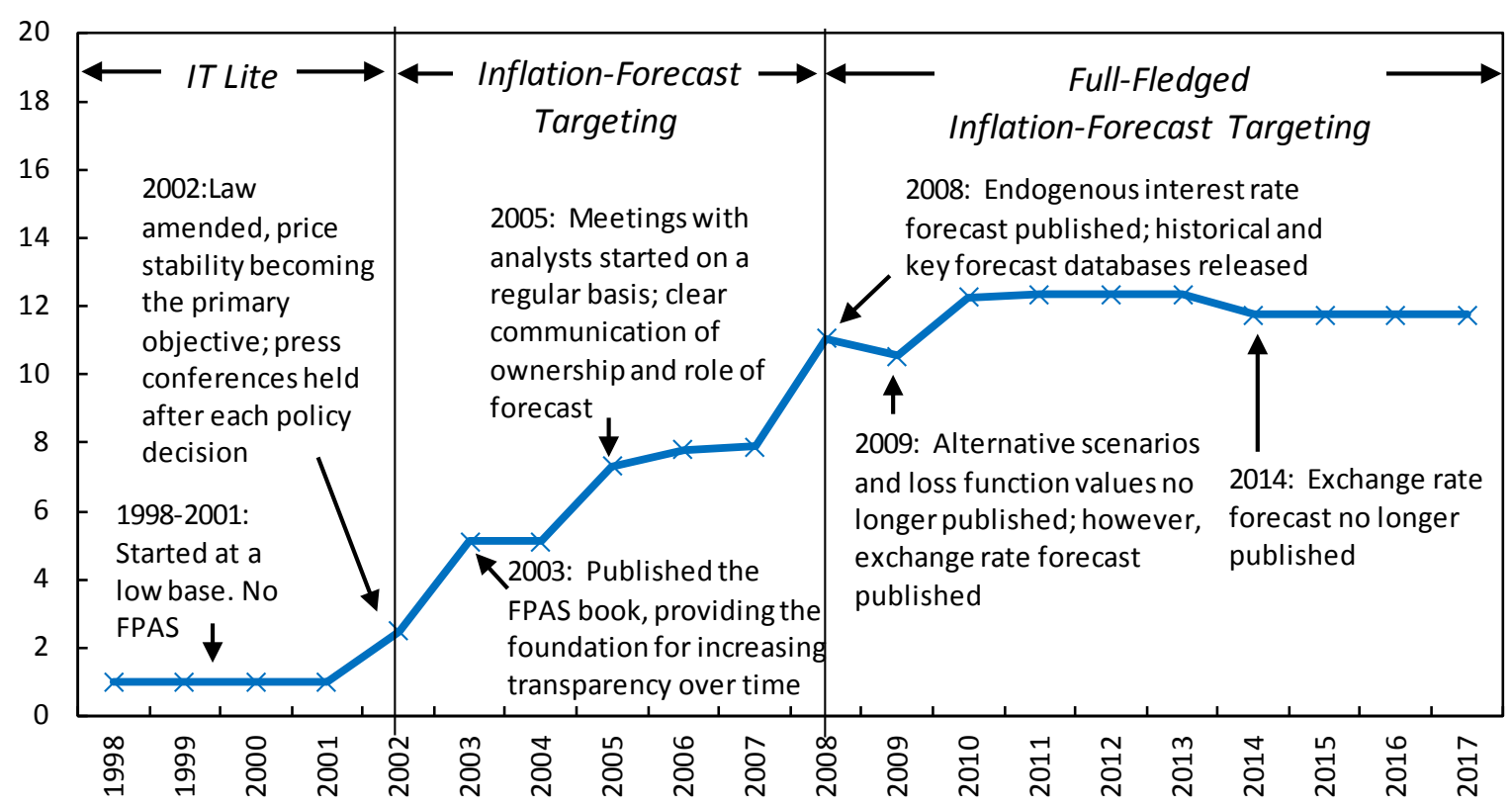

Source: Authors' calculation. 


\section{The FPAS provides the foundation for IFT and increases in transparency (2002-2017)}

The development of the modeling framework provided the foundation for increases in transparency over time and the adoption of IFT in 2002. The critical part of the success of IFT is the development of an analytical framework where the policy rate path (and not just the actual policy rate) is adjusted to achieve the central bank's objectives. Transparency about how the central bank is managing the short-run output-inflation tradeoff is fundamentally what distinguishes IFT central banks from non-IFT central banks. Indeed, as policymakers at the CNB became comfortable over time with the staff's core quarterly projection model and macroeconomic forecast, the $\mathrm{CNB}$ started to reveal more and more details about the forecast and how the model was being used to construct the baseline forecast and alternative scenarios. By 2008, the CNB Board was sufficiently comfortable with the internal forecast process and analytical framework and it decided it would further enhance communications by publishing the forecast of the policy rate path. As shown in Figure 2, this marks the beginning of fullfledged IFT in the Czech Republic. Clinton and others (2017) show that the published interest rate paths were useful in providing forward guidance to financial market participants and argue that publishing interest rate forecasts with confidence bands is a more robust form of forward guidance than the other types of forward guidance that were used by several central banks during the Global Financial Crisis (Alichi and others, 2015b). 
Figure 4. Evolution of the Three Components of the CBT-IT Index for the Czech National Bank, 1998-2017

\section{Panel a. Aggregate and Component Values}

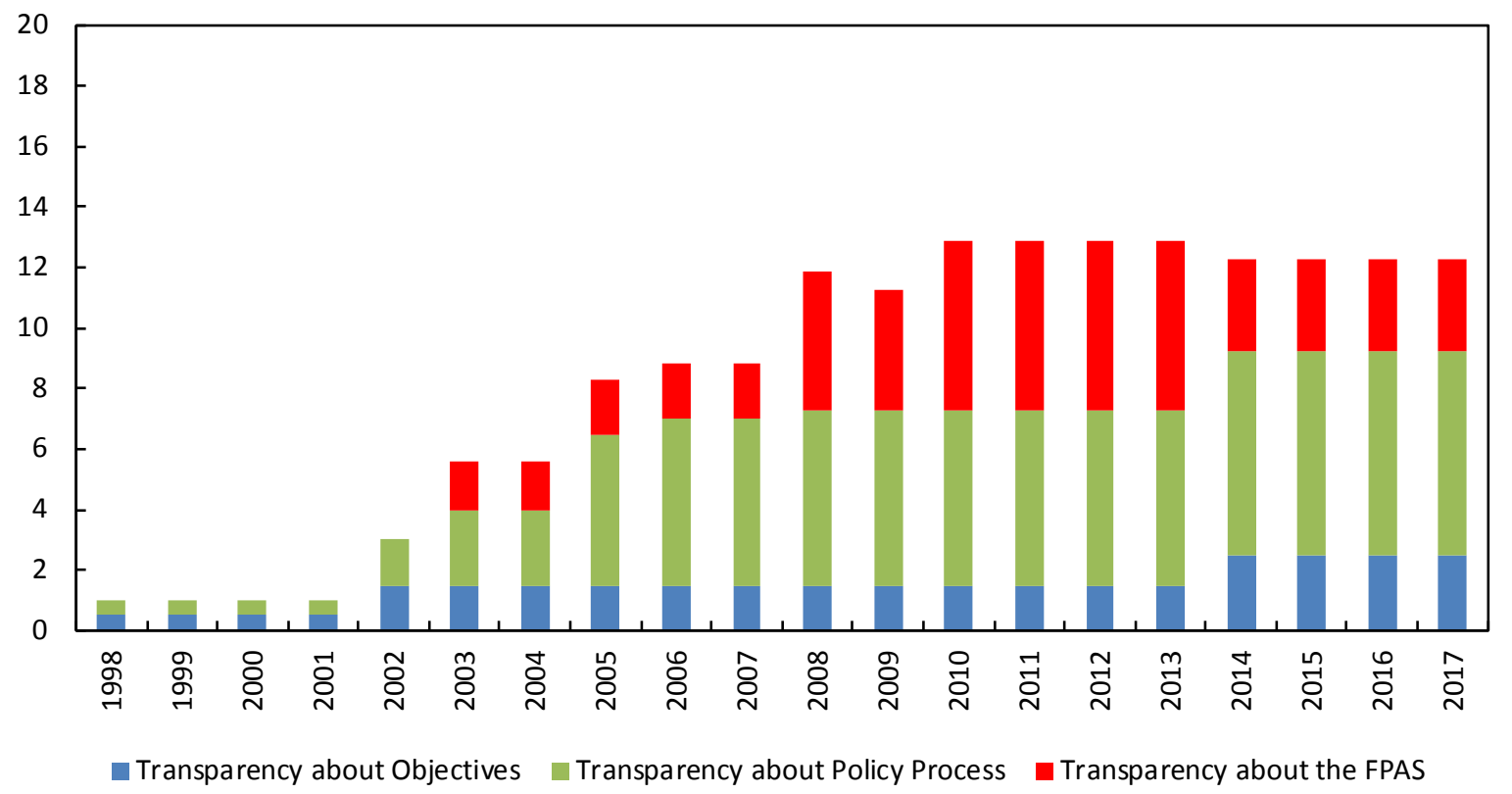

Panel b. Percent of Each Component's Maximum Score

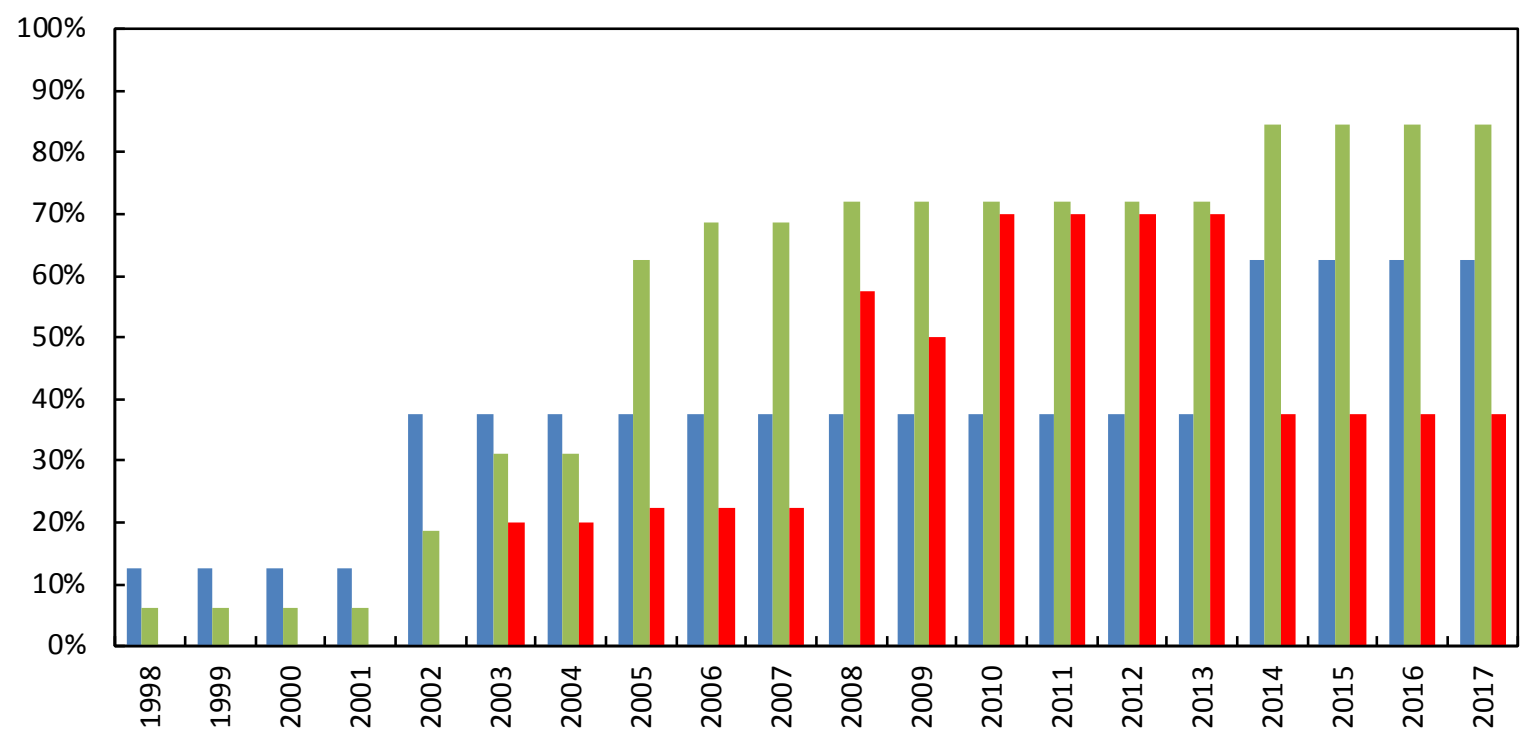

- Transparency about Objectives $\quad$ Transparency about Policy Process $\quad$ Transparency about the FPAS

Source: Authors' calculation. 
Transparency at the CNB has been strengthened over time with efforts directed at making monetary policy deliberations and communications as structured and comprehensible as possible. Indeed, as shown in Figure 2, the CNB's overall CBT-IT index increased from 1 in 1998-2001 to 11.75 out of 20 in 2017. All three components showed significant improvements over time. As documented in Figure 3, transparency about the policy process is particularly high, while the transparency about the FPAS is the category with the largest scope for further improvement.

The rest of the section offers a closer look at how each of the three components of the CBT-IT index has evolved over time.

\section{Category A: Transparency about Objectives (Question A1-A4)}

The pre-1998 monetary policy framework was based on a combination of a pegged exchange rate regime with money targeting. After the May 1997 currency crisis, the central bank was forced to look for a new nominal anchor, and by the end of the year it chose IT. Since the inception of IT, between 1998 and 2017, Category A of the CBT-IT index increased from 0.5 points to 2.5 points.

When IT-lite was introduced in 1998, the CNB's objective was defined as "monetary stability," which was historically interpreted as a combination of internal (i.e. price) and external (i.e. exchange rate) stability. This definition was not consistent with the IT framework. On the contrary, during the post-2007 IFT period the CNB has been explicit about price stability being its primary objective. On the CNB's website, there has been an easily-accessible reference to Central Bank Act No. 6/1993, amended in 2002 ahead of the EU entry, which states that, "The primary objective of the Czech National Bank shall be to maintain price stability. In addition, the Czech National Bank shall work to ensure financial stability and the safe and sound operation of the financial system in the Czech Republic. Without prejudice to its primary objective, the Czech National Bank shall support the general economic policies of the Government leading to sustainable economic growth and the general economic policies in the European Union with a view to contributing to the achievement of the objectives of the European Union." Moreover, these objectives are repeated in the first page of each Inflation Report.

The inflation target started as a range and not a point target in 1998. A point inflation target at 3 percent was announced in spring 2004, and became effective at the beginning of 2006 . However, it was surrounded by a "tolerance band" that could be misinterpreted by some observers as a range target. This practice remained in place when the inflation target was lowered for the last time. In particular, on March 8, 2007, the CNB published a document, entitled: "New inflation target and changes in monetary policy communication," which states that "the CNB announces the new inflation target as annual consumer price index growth of 2 
percent, effective from January 2010. As before, the CNB will strive to ensure that actual inflation does not differ from the target by more than one percentage point on either side." The CNB gets less than a perfect score for Question A2 as the language above would be consistent with a range-targeting central bank. This problem could be easily rectified by using better language, given that the CNB's analytical framework is designed to move inflation back to a point target over the medium term, and the CNB has consistently behaved in line with this.

The primacy of the price stability objective has always been maintained by the CNB even with the formal introduction of the financial stability mandate. The financial stability function was de facto introduced in 2004, but initially with no macroprudential tools to be actively used in policy implementation. Only by 2014 did the CNB become responsible for macroprudential policy by identifying, monitoring, and assessing risks that jeopardize the stability of the financial system. A list of macroprudential policy tools, including countercyclical capital buffers, systemic risk buffer, capital conservation buffer, recommendations on loan-to-value ratios were introduced and started to be used actively. The CNB has both monetary policy and financial stability tools and it makes clear how these tools will be adjusted to achieve the monetary policy and financial stability objectives. In particular, the foreword to the CNB's Inflation Reports currently states: "We use these (i.e. monetary policy) instruments primarily to deliver price stability; to maintain financial stability we use a separate set of instruments called macroprudential tools. However, monetary policy and macroprudential policy affect one another, as monetary policy decisions have an impact on the financial sector and, conversely, macroprudential policy decisions influence the economy and inflation. We therefore take the interactions between the two policies into account." (CNB Inflation Report, $\mathrm{IV} / 2017$ )

This raised the CNB's score for Category A of the CBT-IT index in 2014 to 2.5 points which remained through 2017.

To achieve the perfect score of 4 points for Category A, Transparency about Objectives, the CNB should change the language to clearly explain the role of the bands around the 2 percent target. The language as well as the term "tolerance band" suggests that the CNB is a range targeter. This is inconsistent with the CNB's analytical forecasting framework that adjusts its instruments to guide inflation back to the 2 percent target over the medium term and with the CNB's actual behavior. In addition, the CNB should publish the values of a loss function to show how well it has been managing the output-inflation tradeoff and to show the important progress that has been made improving the efficiency of monetary policy over time.

\section{Category B: Transparency about the FPAS (Question B1-B9)}

The CNB embarked on IT without an appropriate infrastructure or forecasting methods (see Coats, Laxton and Rose, 2003). It had to rely on the data-driven near-term forecasting methods, and expert judgment. Inadequate forecasting methods, together with the volatile 
macroeconomic environment and unstable inflation expectations, contributed to very large forecast errors in the initial years of inflation targeting (Holub and Hurník, 2008; Šmídková, ed., 2008).

As a result of these forecast errors, the incentives were created to develop a new FPAS, with a medium-term focus, and an active role for monetary policy. Implementing the FPAS in mid2002, and publishing a book documenting it in 2003 resulted in an improvement in Category $\mathrm{B}$ of the CBT-IT index from 0 points to 1.6 points. The QPM-Gap, a small-scale calibrated monetary policy model for the Czech Republic, was developed over 3 years, with technical assistance from the IMF. The switch to QPM-Gap can be regarded as the start of IFT in the Czech Republic: QPM-Gap had the appropriate medium-term focus; it included forwardlooking channels; the monetary policy transmission mechanism had an internal channel (through a forward-looking interest rate term structure), and an external channel (through the exchange rate); and last but not the least, it had the all-important endogenous short-term interest rate equation designed to move inflation gradually back to the target. At the same time, the CNB started to publish model-based endogenous forecasts for inflation and GDP growth. In 2007, the CNB made all the data used in the Inflation Report publicly available.

The period that followed was especially important for Category B of the CBT-IT index, which went up from 1.6 points to 4.8 points. The QPM-Gap was replaced with a DSGE model (QPMg3) in mid-2008. It was the first time an IFT central bank used a DSGE model as the core projection model in its FPAS. The CNB documented and published the model in a working paper (Andrle and others, 2009). Moreover, at the beginning of 2008 the CNB started publishing fan charts for the policy rate path. One year later, i.e. in 2009, the CNB started publishing the koruna-euro exchange rate projection with fan charts. The CNB also published alternative scenarios and sensitivity analysis in each Inflation Report.

There was a slight retrenchment in the score of Category B in 2014, as the CNB stopped publishing the exchange rate forecast and alternative scenarios, which were replaced by communicating the level of the exchange rate commitment (27 CZK/EUR; see Franta and others, 2014), as well as the expected duration of the commitment. At the same time, the working paper on the core forecasting model became more than 5 years old, i.e., too outdated to meet the suggested transparency criteria for the FPAS.

In 2017 the CNB scored 3.5 points out of 9 for Category B of the CBT-IT index. To obtain the perfect score of 9, the CNB should publish its core model with the coefficients and code to allow the users to replicate the forecasts. Besides, the CNB should start publishing baseline forecasts with fan charts for the output gap and alternative scenarios, regularly in the Inflation Reports. The CNB resumed the publication of the exchange rate forecast of koruna to euro in February, which will increase its score for Category B for 2018. 


\section{Category C: Transparency about Policy Process (Question C1-C7)}

Over time the CNB has broadened, deepened, and provided more timely communications on its policy actions. The score on the transparency of the policy process was only 0.5 points between 1998 and 2001 and increased to 5.75 in 2017.

The Board issues a press release immediately after the decision is taken, and the Governor gives a press conference the same afternoon. The monetary policy decision is explained either in the context of a new macroeconomic forecast (four times a year), or, for inter-forecast policy meetings, of a risk assessment to the previous quarterly forecast (also four times a year since 2008). The presentations give the votes cast by the Board members on interest rate decisions.

Since 2014, the Governor has provided a written explanation of the decision, followed by a Q\&A session. Eight days after the policy meeting, the CNB publishes the Minutes (with the individual votes since 2008), and the Inflation Report, which has all the details of the forecast. Over time, the structure of the Inflation Report has evolved to put more emphasis upfront on the forward-looking content, and to deliver more concise messages. Another regular means of communication is a schedule of quarterly meetings with financial market analysts (both local and foreign), at which senior staff presents the new macroeconomic forecast, followed by a discussion with senior staff and one or two Board members. These meetings now take place one day after the policy decision announcement, along with the release of the Executive Summary of the Inflation Report, which includes a detailed forecast table. The meetings are web-casted live on the CNB's website.

The ownership of the forecast and the role of the staff and the policy makers in the decisionmaking process are defined clearly at the $\mathrm{CNB}$ and that improves the score for Category $\mathrm{C}$ of the CBT-IT. ${ }^{12}$

To get the perfect score of 7 for the Category C of the CBT-IT index, the contributions of the individual MPC members should be clearly attributed. In addition, an external evaluation of the policy framework and FPAS should be carried out at least once every five years.

\section{Conclusion}

This paper develops a more ambitious central bank transparency index compared to Dincer and Eichengreen (2014), and helps to establish transparency benchmarks that reflect best practices at the most advanced IFT central banks. The components of the CBT-IT include measures of transparency about monetary policy objectives, the FPAS designed to support IFT, and the monetary policymaking process.

\footnotetext{
${ }^{12}$ For an early review of CNB communication transparency and clarity, see Šmídková and Bulíř (2007).
} 
When applied to the $\mathrm{CNB}$, the progress achieved by the bank on each of the components of the index has been clearly identified. After starting with a score of 1 out of 20 during 1998-2001, the development of the modeling framework and the documentation of the FPAS provided the foundation for improvements in transparency over time and the adoption of IFT in 2002, increasing the score more than five-fold by 2003. Moreover, transparency at the CNB has been strengthened over time with efforts directed at making monetary policy deliberations and communications as structured and comprehensible as possible. The CNB's overall CBT-IT index increased to 11.75 in 2017. Similar to the Dincer-Eichengreen index, our CBT-IT index scores the CNB at high levels, but suggests that there are a few areas where the CNB could further improve transparency. All three components of the index have shown significant improvements over time. However, transparency about the policy process is particularly high in the CNB's case, while the transparency about the FPAS is the category with the largest scope for further improvement. The CNB already has plans to improve monetary policy transparency in some of the areas identified in this paper. 


\section{APPENDIX I: DinCER-EICHENGREEN CENTRAL BANK TRANSPARENCY QUESTIONS}

\section{Political Transparency}

(a) Is there a formal statement of the objective(s) of monetary policy, with an explicit prioritization in case of multiple objectives?

No formal objective $(\mathrm{s})=0$.

Multiple objectives without prioritization $=1 / 2$.

One primary objective, or multiple objectives with explicit priority $=1$.

(b) Is there a quantification of the primary objective(s)?

$$
\begin{aligned}
& \text { No }=0 . \\
& \text { Yes }=1 .
\end{aligned}
$$

(c) Are there explicit contacts or other similar institutional arrangements between the monetary authorities and the government?

No central bank contracts or other institutional arrangements $=0$.

Central bank without explicit instrument independence or $\operatorname{contract}=1 / 2$.

Central bank with explicit instrument independence or central bank contract although possibly subject to an explicit override procedure $=1$.

\section{Economic Transparency}

(a) Is the basic economic data relevant for the conduct of monetary policy publicly available? (The focus is on the following five variables: money supply, inflation, GDP, unemployment rate and capacity utilization.)

Quarterly time series for at most two out of the five variables $=0$.

Quarterly time series for three or four out of the five variables $=1 / 2$.

Quarterly time series for all five variables $=1$.

(b) Does the central bank disclose the macroeconomic model(s) it uses for policy analysis?

No $=0$.

Yes $=1$.

(c) Does the central bank regularly publish its own macroeconomic forecasts?

No numerical central bank forecasts for inflation and output $=0$.

Numerical central bank forecasts for inflation and/or output published at less than quarterly frequency $=1 / 2$. 
Quarterly numerical central bank forecasts for inflation and output for the medium term (one to two years ahead), specifying the assumptions about the policy instrument (conditional or unconditional forecasts) $=1$.

\section{Procedural Transparency}

(a) Does the central bank provide an explicit policy rule or strategy that describes its monetary policy framework?

$$
\begin{aligned}
& \text { No }=0 . \\
& \text { Yes }=1 .
\end{aligned}
$$

(b) Does the central bank give a comprehensive account of policy deliberations (or explanations in case of a single central banker) within a reasonable amount of time?

No or only after a substantial lag (more than eight weeks) $=0$.

Yes, comprehensive minutes (although not necessarily verbatim or attributed) or explanations (in case of a single central banker), including a discussion of backward- and forward-looking arguments $=1$.

(c) Does the central bank disclose how each decision on the level of its main operating instrument or target was reached?

No or only after a substantial lag (more than eight weeks) $=0$.

Yes, comprehensive minutes (although not necessarily verbatim or attributed) or explanations (in case of a single central banker), including a discussion of backward- and forward-looking arguments $=1$.

\section{Policy Transparency}

(a) Are decisions about adjustments to the main operating instrument or target announced promptly?

No or only after the day of implementation $=0$.

Yes, on the day of implementation $=1$.

(b) Does the central bank provide an explanation when it announces policy decisions?

$\mathrm{No}=0$.

Yes, when policy decisions change, or only superficially $=1 / 2$.

Yes, always and including forwarding-looking assessments $=1$. 
(c) Does the central bank disclose an explicit policy inclination after every policy meeting or an explicit indication of likely future policy actions (at least quarterly)?

$$
\begin{aligned}
& \text { No }=0 . \\
& \text { Yes }=1 .
\end{aligned}
$$

\section{Operational Transparency}

(a) Does the central bank regularly evaluate to what extent its main policy operating targets (if any) have been achieved?

No or not very often (at less than annual frequency) $=0$.

Yes but without providing explanations for significant deviations $=1 / 2$.

Yes, accounting for significant deviations from target (if any); or, (nearly) perfect control over main operating instrument/target $=1$.

(b) Does the central bank regularly provide information on (unanticipated)

macroeconomic disturbances that affect the policy transmission process?

No or not very often $=0$.

Yes but only through short-term forecasts or analysis of current macroeconomic developments (at least quarterly) $=1 / 2$.

Yes, including a discussion of past forecast errors (at least annually) $=1$.

(c) Does the central bank regularly provide an evaluation of the policy outcome in light of its macroeconomic objectives?

No or not very often (at less than annual frequency) $=0$.

Yes but superficially $=1 / 2$.

Yes, with an explicit account of the contribution of monetary policy in meeting the objectives $=1$. 


\title{
APPENDIX II: CBT-IT INDEX QUESTIONS
}

\section{Category A: Transparency about Objectives}

\begin{abstract}
A1. Is there a formal statement of the objectives of monetary policy emphasizing the dual mandate (or multiple objectives), and that inflation is the primary objective? Is it easily accessible on the central bank's website?
\end{abstract}

Single inflation objective or multiple policy objectives without prioritization.

Inflation as the primary objective such that any other objective (output, etc.) cannot be inconsistent with the primary objective of anchoring inflation and inflation expectations.

Example-CNB: "Under Article 98 of the Constitution of the Czech Republic and in line with EU primary law, the primary objective of the CNB is to maintain price stability. 


\begin{tabular}{|c|c|}
\hline \multicolumn{2}{|l|}{ A2. Is the inflation target defined clearly? } \\
\hline $\begin{array}{l}\text { No medium-term numerical target over a horizon of } 2-3 \text { years or more (hereafter } \\
\text { medium term). }\end{array}$ & 0.0 \\
\hline $\begin{array}{l}\text { Inflation target defined as a "tolerance" or "control range" target. } \\
\text { Inflation target defined as a medium-term target, however, the meaning of the } \\
\text { range or the band is not clear. }\end{array}$ & 0.5 \\
\hline $\begin{array}{l}\text { Inflation target defined as a well-defined point target. If a band is used, it is clearly } \\
\text { communicated. } \\
\text { Example - Riksbank: "Although the aim is that inflation shall be } 2 \text { per cent, } \\
\text { outcomes will always vary around the target. To illustrate in a simple manner the } \\
\text { fact that monetary policy has little ability to steer inflation in detail, the Riksbank } \\
\text { uses a variation band in its monetary policy communication with effect from } \\
\text { September 2017. A variation band that stretches between } 1 \text { and } 3 \text { per cent } \\
\text { captures approximately three-quarters of outcomes for CPIF inflation since mid- } \\
\text { 1995. The variation band does not affect the formulation of monetary policy. The } \\
\text { Riksbank always aims for } 2 \text { per cent inflation, regardless of whether inflation is } \\
\text { initially inside or outside the variation band." }\end{array}$ & 1.0 \\
\hline
\end{tabular}




\begin{tabular}{|c|c|}
\hline \multicolumn{2}{|l|}{$\begin{array}{l}\text { A3. Might financial stability objectives override the primacy of the inflation (price } \\
\text { stability) objective? If the central bank does not have a financial stability } \\
\text { responsibility, it should be explicit that it uses the policy interest rate tool to affect } \\
\text { financial conditions to the extent that it affects the output gap and hence achieving } \\
\text { the inflation target. }\end{array}$} \\
\hline (i) $\quad$ Another institution is responsible for financial stability. & \\
\hline $\begin{array}{l}\text { Central bank cares about financial stability to the extent that it affects stabilization } \\
\text { objectives (output and unemployment), but it is unclear that inflation is the } \\
\text { primary objective. } \\
\text { Example-uses language such as "lean against the wind". }\end{array}$ & 0.0 \\
\hline $\begin{array}{l}\text { Central bank cares about financial stability to the extent that it affects stabilization } \\
\text { objectives (output and unemployment), and makes it clear that inflation is the } \\
\text { primary objective. }\end{array}$ & 1.0 \\
\hline Central bank is at least partly responsible for financial stability. & \\
\hline $\begin{array}{l}\text { The borderlines between the monetary policy and financial stability tools are } \\
\text { unclear. This creates confusion about the primary objective of price stability. }\end{array}$ & 0.0 \\
\hline $\begin{array}{l}\text { The central bank has both monetary policy and macroprudential tools and it is } \\
\text { clear how the central bank adjusts its tools to achieve its monetary policy and } \\
\text { financial stability objectives. }\end{array}$ & 1.0 \\
\hline
\end{tabular}


A4. Does the central bank use a loss function evaluation to show how well it has been doing in managing the short-run output-inflation tradeoff?

\begin{tabular}{|l|l}
\hline & 0.0
\end{tabular}

No.

Yes. 


\section{Category B: Transparency about the FPAS}

\section{B1. Are the basic economic data relevant for the conduct of monetary policy publicly available in a downloadable format from the central bank's website (could also include links to other statistical agencies)? For example, data reported in the monetary policy reports should be made available on the website.}

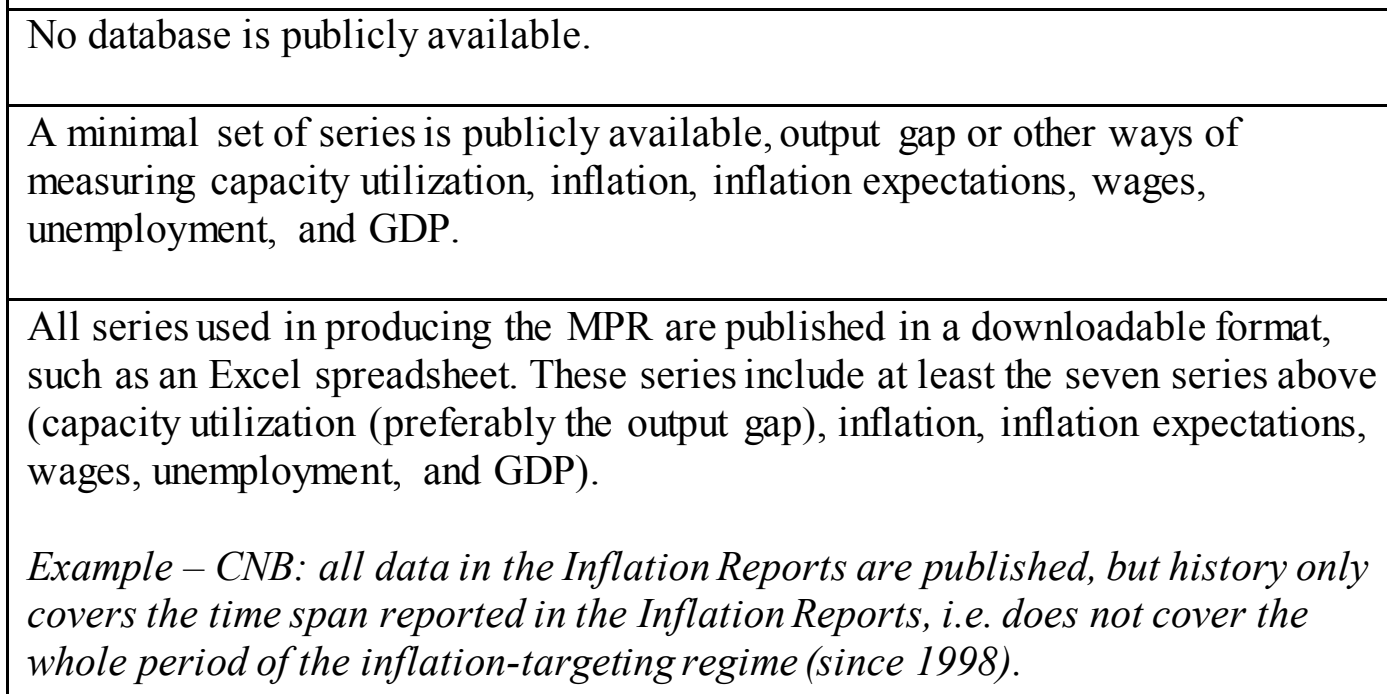

All series used in producing the MPR are published in a downloadable format, 
B2. Is the core quarterly projection model (model used for policy-making) publicly available and documentation updated within the last 5 years?

\begin{tabular}{|l|l|}
\hline No. & 0.00 \\
\hline Yes, in a "working paper" format only, i.e., irreproducible. & 0.25 \\
\hline Yes, in a working paper and with code. & 0.50 \\
\hline $\begin{array}{l}\text { Yes, in a working paper, with code, and web-based front-end to modify forecast } \\
\text { assumptions. }\end{array}$ & 1.00 \\
$\begin{array}{l}\text { Example-none. } \\
\text { Nate }\end{array}$ &
\end{tabular}


B3. How transparent is the central bank about the reaction functions (or loss functions) that are used to compute the interest rate paths (or paths for other instruments when the policy rate is constrained by the ELB) in their regular projection exercises? Do the monetary policy reports include a reference to the core model documentation that has the reaction function or the loss function?

The central bank does not publish either the reaction function or the loss function. 0.0

The central bank publishes the reaction function and/or loss function (with the coefficients) in an easily accessible place on the central bank's website. 1.0 


\begin{tabular}{|l|l|}
\hline $\begin{array}{l}\text { B4. For what variables does the central bank publish a consistent endogenous- } \\
\text { instrument (e.g., policy rate) quarterly macroeconomic projection over a horizon of } \\
\text { at least two years? }\end{array}$ & 0.0 \\
\hline None. & 0.2 \\
\hline Inflation. & 0.4 \\
\hline Inflation and GDP growth. & 0.6 \\
\hline Inflation, GDP growth, and the endogenous interest rate path. & 0.8 \\
\hline Inflation, GDP growth, the endogenous interest rate path, and the output gap. \\
\hline $\begin{array}{l}\text { Inflation, GDP growth, the endogenous interest rate path, the output gap, and the } \\
\text { exchange rate. }\end{array}$ & 1.0 \\
\hline
\end{tabular}




\begin{tabular}{|l|l|}
\hline $\begin{array}{l}\text { B5. Does the central bank regularly publis h forecast densities (fan charts) to } \\
\text { communicate forecast uncertainty? }\end{array}$ & 0.0 \\
\hline No fan chart. & 0.2 \\
\hline Fan chart for inflation. & 0.4 \\
\hline Fan charts for inflation and GDP growth. & 0.6 \\
\hline Fan charts for inflation, GDP growth, and the endogenous interest rate path. \\
\hline $\begin{array}{l}\text { Fan charts for inflation, GDP growth, the endogenous interest rate path, and the } \\
\text { output gap. }\end{array}$ & 0.8 \\
\hline $\begin{array}{l}\text { Fan charts for inflation, GDP growth, the endogenous interest rate path, the } \\
\text { output gap, and the exchange rate. }\end{array}$ & 1.0 \\
\hline
\end{tabular}


B6. Is the underlying methodology constructing the forecast densities (fan charts) clear and easily accessible?

For example, do the regularly published forecast densities (fan charts) reflect (i) monetary policy reaction to shocks (model-based stochastic simulations); (ii) historic experience (past forecast errors); (iii) judgment (e.g., magnitude of structural shocks versus measurement errors); and (iv) other constraints (e.g., effective lower bound)?

No fan chart, or the fan chart methodology is not explained.

Fan charts published in all monetary policy reports and the methodology is 1.0 clearly explained and/or links to a technical paper is provided. 


\begin{tabular}{|l|l|}
\hline $\begin{array}{l}\text { B7. Does the central bank regularly publish an assessment of forecast revisions } \\
\text { (decomposition of forecast changes vis-à-vis the previous forecast)? }\end{array}$ \\
\hline No. & 0.0 \\
\hline For inflation only with a discussion of the underlying causes. & 0.2 \\
\hline For inflation and GDP growth with a discussion of the underlying causes. & 0.4 \\
\hline $\begin{array}{l}\text { For inflation, GDP growth, and the endogenous interest rate path with a discussion } \\
\text { of the underlying causes. }\end{array}$ & 0.6 \\
\hline $\begin{array}{l}\text { For inflation, GDP growth, the endogenous interest rate path, and the output gap } \\
\text { with a discussion the underlying causes. }\end{array}$ & 0.8 \\
\hline $\begin{array}{l}\text { For inflation, GDP growth, the endogenous interest rate path, the output gap, and } \\
\text { the exchange rate with a discussion the underlying causes. }\end{array}$ & 1.0 \\
\hline
\end{tabular}


B8. Does the central bank publish alternative scenarios in their monetary policy reports to illustrate key risk(s) in the baseline forecast?

No alternative scenario.

0.0

The major risk(s) is communicated in an alternative scenario(s). 
B9. Do the monetary policy reports include historical data and forecasts for financial variables? Financial variables include long-term government bond yields, consumer lending rates, mortgage rates, equity prices, property prices, credit aggregates, corporate risky spreads (e.g., BAA-AAA bond yields), and credit standards (e.g., loan officer surveys). All data should be available in downloadable format.

\begin{tabular}{|l|l}
\hline No data or forecast of financial variables are available. & 0.0
\end{tabular}

\begin{tabular}{|l|l|} 
Historical data on less than 5 of the above variables are available, and forecasts & $0.1-0.9 *$
\end{tabular} for less than 5 of the above variables are available.

Historical data on 5 or more of the above variables are available, and forecasts for 5 or more of the above variables are available.

* For historical series, the central bank would be awarded 0.1 for each type of financial variables up to a maximum of 0.5 .

For forecast series, the central bank would be awarded 0.1 for each type of financial variables up to a maximum of 0.5 . 
Category C: Transparency about Policy Process

C1. Does the central bank publish a press statement immediately following the policy decisions?

The central bank does not publish a press statement immediately after the policy

0.0

decisions.

The central bank publishes press statements in the native language only.

0.5

The central bank publishes press statements in English.

1.0




\section{C2. Is the policy decision explained at a press conference immediately after it is announced? Are the presentations available in English?}

\begin{tabular}{|c|c|}
\hline No. & 0.0 \\
\hline $\begin{array}{l}\text { Yes, after all policy meetings, at pre-announced dates and times. The press } \\
\text { conference with the Q\&A session is webcasted and the recording is then made } \\
\text { available on the website. The presentations are available in downloadable form } \\
\text { only in the native language. }\end{array}$ & 0.5 \\
\hline $\begin{array}{l}\text { Yes, after all policy meetings, at pre-announced dates and times. The press } \\
\text { conference with the Q\&A session is webcasted and the recording is then made } \\
\text { available on the website. The presentations are available in downloadable form in } \\
\text { English. } \\
\text { Example - Norges Bank: The interest rate decisions are announced at a pre- } \\
\text { determined date, after all policy meetings. Press conference is available on the } \\
\text { website at http://www. norges-bank.no/en/Monetary-policy/Monetary-policy- } \\
\text { meetings/2016/Rate-decision-May-2016/. }\end{array}$ & 1.0 \\
\hline
\end{tabular}


C3. Does the central bank present its regular forecast updates with the $Q \& A$ session to journalists, analysts, and market participants? Are the presentations available in English?

No.

0.0

Yes. The presentation and Q\&A are available only in the native language.

Yes. The presentation and Q\&A are available in English.

Example - Czech National Bank: regular meetings with analysts 
C4. Is there a public account of the policy deliberations ("minutes") published in less than one month after the meeting?

(i) when policy decisions are made by a monetary policy committee

\begin{tabular}{|l|l|}
\hline No. & 0.00 \\
\hline Yes, but condensed, non-attributed, and without voting results. & 0.50 \\
\hline $\begin{array}{l}\text { Yes, detailed and with voting results on the main policy instrument. } \\
\text { Contributions by individual MPC members and votes are not attributed. }\end{array}$ & 0.75 \\
\hline $\begin{array}{l}\text { Yes, detailed and with voting results on the main policy instrument. } \\
\text { Contributions by individual MPC members and votes are attributed. }\end{array}$ & 1.00 \\
\hline \multicolumn{1}{|c|}{ when policy decisions are made by a single policymaker } & \\
\hline No. & 0.00 \\
\hline Yes, with arguments/explanations. & 1.00 \\
\hline
\end{tabular}




\section{C5. Is the role of staff and policymakers in the baseline forecast process communicated clearly?}

No. It is not clear how the forecast is constructed and is used in the decisionmaking process.

Yes. The ownership of the forecast and its role in the decision-making process is defined clearly.

Example - CNB: "The forecast is the key, but not the only, input to our monetary policy decision-making. Unless the economic situation requires an extraordinary monetary policy meeting, the Bank Board meets eight times a year to discuss monetary policy issues. At four of the meetings (in February, May, August and November) we discuss a new forecast, while at the other four (in March, June, September and December) we discuss the risks and uncertainties of the most recent forecast in the light of newly available information on domestic and foreign economic developments. Due to the arrival of new information since the forecast was drawn up and to the possibility of the Bank Board members assessing its risks differently, the decision we adopt may not fully correspond to the message of the forecast prepared by our experts." (Foreword of the CNB Inflation Report IV/2017). 
C6. Is the forecasting performance of the central bank reviewed at least once a year in the monetary policy reports or in a separate document?

\begin{tabular}{|l|l}
\hline No. & 0.0
\end{tabular}

Yes. 
C7. When was the last time the central bank or the government held or invited an external evaluation of the policy framework and the FPAS, and made the results publicly available?

\begin{tabular}{|l|l}
\hline No evaluation in last 5 years. & 0.0
\end{tabular}

\begin{tabular}{|l|l}
\hline Either policy framework or FPAS evaluation in the last 5 years. & 0.5
\end{tabular}

Both policy framework and FPAS evaluation in the last 5 years.

1.0

Example-None. 


\title{
APPENDIX III: CBT-IT INDEX SCORE FOR THE CZECH NATIONAL BANK IN 2017
}

This appendix applies the CBT-IT questions to the Czech National Bank (CNB) in 2017 and scores the CNB at 11.75 out of 20 . Staff at the CNB were given a chance to provide comments and in most cases presented the CNB's envisaged future plans to strengthen its transparency modalities consistent with the frontiers of IT.

\begin{abstract}
A1. Is there a formal statement of the objectives of monetary policy emphasizing the dual mandate (or multiple objectives), and that inflation is the primary objective? Is it easily accessible on the central bank's website?

Perfect score requires: The objectives are clear and accessible on the central bank's website.

CNB Score: $1 / 1$

Details: On the CNB's website, there was an easily accessible reference to Central Bank Act No. 6/1993, which states that, "The primary objective of the Czech National Bank shall be to maintain price stability. In addition, the Czech National Bank shall work to ensure financial stability and the safe and sound operation of the financial system in the Czech Republic. Without prejudice to its primary objective, the Czech National Bank shall support the general economic policies of the Government leading to sustainable economic growth and the general economic policies in the European Union with a view to contributing to the achievement of the objectives of the European Union." Moreover, this statement is repeated on the first page of each Inflation Report.
\end{abstract}

Recommendations: In connection to explicitly publishing and explaining the dual mandate with prioritization, the United States Federal Reserve Bank's one-pager document provides an illustrative example that could be considered by the CNB going forward.

https://www.federalreserve.gov/monetarypolicy/files/FOMC LongerRunGoals.pdf Moreover, given that monetary policy is not only about achieving the inflation target, but more generally must consider the implications on output, the Inflation Report could be renamed as the Monetary Policy Report.

CNB comments: The CNB Board has approved a project aimed at switching from an Inflation Report to a Monetary Policy Report in 2019-20. This step is designed to extend beyond just renaming the report but rather focusing on explaining the importance of price stability, the role of monetary policy in achieving it, the uncertainty, as well as tradeoffs that monetary policy has to deal with when faced by macroeconomic shocks. 


\section{A2. Is the inflation target defined clearly? \\ Perfect score requires: The central bank should explicitly announce a well-defined point target and clearly explain the role of the bands (if any).}

\section{CNB Score: 0.5/1}

Details: On March 8, 2007, the CNB published a document, entitled: "New inflation target and changes in monetary policy communication", which states that "the CNB announces the new inflation target as annual consumer price index growth of 2 percent, effective from January 2010. As before, the CNB will strive to ensure that actual inflation does not differ from the target by more than one percentage point on either side. The CNB continues to view its inflation target as a medium-term one which actual inflation may deviate from temporarily as a result of exogenous shocks. Changes to indirect taxes are one such shock; monetary policy does not react to the first-round effects of such changes and concentrates only on their second-round effects."

https://www.cnb.cz/miranda2/export/sites/www.cnb.cz/en/monetary policy/strategic docu ments/download/inflacni cil cnb en 2010.pdf

Recommendations: Change the language to explicitly announce a well-defined point target and clearly explain the role of the bands. An example would be the precise language used by the Riksbank: "Although the aim is that inflation shall be 2 percent, outcomes will always vary around the target. To illustrate in a simple manner the fact that monetary policy has little ability to steer inflation in detail, the Riksbank uses a variation band in its monetary policy communication with effect from September 2017. A variation band that stretches between 1 and 3 per cent captures approximately three-quarters of outcomes for CPIF inflation since mid-1995. The variation band does not affect the formulation of monetary policy. The Riksbank always aims for 2 per cent inflation, regardless of whether inflation is initially inside or outside the variation band."

http://www.riksbank.se/en/Monetary-policy/Inflation/Adoption-of-the-inflation-target/

CNB comments: Staff of the CNB judge that the bank has systematically behaved as a point targeter. This is reflected in the reaction function within the forecasting model, which has explicitly aimed at achieving the 2 percent point target. Staff argue that the band of $+/-$ one percentage point is meant to communicate the uncertainty faced by the central bank, not a range of inaction. Staff claim that while the term "tolerance band" used by the CNB is a legacy of the past and may be inferior to the term "variation band" used by the Riksbank, there is no fundamental difference between the two concepts. However, staff emphasize that the CNB may reconsider this in the future. 


\begin{abstract}
A3. Might financial stability objectives override the primacy of the inflation (price stability) objective? If the central bank does not have a financial stability responsibility, it should be explicit that it uses the policy interest rate tool to affect financial conditions to the extent that it affects the output gap and hence achieving the inflation target.

Perfect score requires: If another institution is responsible for financial stability, it should make clear that inflation is still the primary objective. If the central bank is at least partly responsible for financial stability, it should have both adequte monetary policy and financial stability tools, and make clear how these tools will be adjusted to achieve the monetary policy and financial stability objectives.
\end{abstract}

\title{
CNB Score: $1 / 1$
}

Details: On the CNB's website, it was stated that in addition to achieving the price stability objective, financial stability is also an objective. Moreover, the CNB was responsible for setting the macroprudential policy by identifying, monitoring and assessing risks that jeopardize the stability of the financial system. There was a list of macroprudential policy tools, including: countercyclical capital buffers, systemic risk buffer, capital conservation buffer, recommendations on loan-to-value ratios.

http://www.cnb.cz/miranda2/export/sites/www.cnb.cz/en/legislation/official_information/v estnik 2017 $07 \quad 20717180$ en.pdf

CNB comments: Staff of the CNB judge that the macroprudential toolkit has so far been deemed sufficient to face potential financial cycles. However, the CNB aims to strengthen its macroprudential tools by adding binding regulations on LTV, DTI and DSTI ratios. This ammendment to the law was not passed by the previous Parliament but there were plans to resubmit it after the general elections are held in October 2017. 
A4. Does the central bank use a loss function evaluation to show how well it has been doing in managing the short-run output-inflation tradeoff?

Perfect score requires: The central bank should publish the values of the loss function and represent the $m$ in a chart (see Figure 7 in Clinton and others, 2017).

CNB Score: 0/1

Details: In 2008, the CNB published a research which contained an evaluation of the Bank's performance using a loss function (Evaluation of the Fulfillment of the CNB's Inflation Targets 1998-2007, Chapter 2, page 25). However, it was not a policy document.

Recommendations: Such loss function evaluation could become part of the future monetary policy reports on a regular basis. 
B1. Are the basic economic data relevant for the conduct of monetary policy publicly available in a downloadable format from the central bank's website (could also include links to other statistical agencies)? For example, data reported in the monetary policy reports should be made available on the website.

Perfect score requires: All series used in producing the monetary policy reports are published in a downloadable format, such as an Excel spreadsheet. These series include at least the following six series: capacity utilization (preferably the output gap), inflation, inflation expectations, wages, unemployment, and GDP).

CNB Score: $1 / 1$

Details: All series used in producing the Inflation Report were published in a downloadable format, in an Excel spreadsheet. These series included the capacity utilization, inflation, inflation expectations, wages, unemployment, and GDP. 


\begin{abstract}
B2. Is the core quarterly projection model (model used for policy-making) publicly available and documentation updated within the last 5 years?

Perfect score requires: The central bank should publish the model in a working paper, provide the code, and create a web-based front-end for users to modify forecast assumptions. In addition, the documentation should be updated within the last 5 years.
\end{abstract}

\title{
CNB Score: 0/1
}

Details: The CNB has a published paper which dates back to 2009, entitled "Implementing the New Structural Model of the Czech National Bank" by Michal Andrle, Tibor Hlédik, Ondra Kameník and Jan Vlček. However, this paper is not referenced in the Inflation Report.

http://www.cnb.cz/miranda2/export/sites/www.cnb.cz/en/research/research publications/c nb_wp/download/cnbwp_2009_02.pdf

Recommendations: We would like to highlight the case of the Riksbank where the forecasting model (Ramses II) as well as the codes are published on the bank's website (see the link below).

http://www.riksbank.se/sv/Press-och-publicerat/Publicerat-fran-Riksbanken/Ovrigarapporter/Occasional-Paper-Series/2013/No-12-Ramses-II--Model-Description/

CNB comments: The CNB provided the core model's equations and its coefficients opon request. The demand was generated mainly by the academia. There is a plan, however, to introduce an extended version of the core forecasting model, publish its documentation, and keep it up to date on the CNB's webpage in 2018. This is expected to be accompanied by material on how the model is being used in the forecasting exercise as part of the FPAS process. 


\section{B3. How transparent is the central bank about the reaction functions (or loss functions) that are used to compute the interest rate paths (or paths for other instruments when the policy rate is constrained by the ELB) in their regular projection exercises? Do the monetary policy reports include a reference to the core model documentation that has the reaction function or the loss function? \\ Perfect score requires: The central bank should publish the reaction function or the loss function and include in the monetary policy reports a reference to the documentation.}

\section{CNB Score: $0 / 1$}

Details: As mentioned in the previous question, the working paper containing the core model was very old and was not easily accessible on the CNB's website. In addition, the Inflation Report does not include a reference to the core model documentation that has the loss function or reaction function.

CNB comments: Staff from the CNB argued that the reaction function used in the current model had been published in its general form, but without the coefficient values. The coefficient values will be provided in the documentation of the extended model (see CNB comments for question B2). Staff highlighted that the CNB added no judgments to its interest rate path, unless the ELB was binding. 
B4. For what variables does the central bank publish a consistent endogenousinstrument (e.g., policy rate) quarterly macroeconomic projection over a horizon of at least two years?

Perfect score requires: The central bank should publish a consistent endogenousinstrument (e.g., policy rate) quarterly macroeconomic projection over a horizon of at least two years, including variable such as inflation, GDP growth, the endogenous interest rate path, the output gap, and the exchange rate.

CNB Score: $0.8 / 1$

Details: With the exception of the exchange rate series, the CNB published the remaining four macroeconomic series. Therefore, it got less than full score.

CNB comments: The CNB started publishing the exchange rate projection $(\mathrm{CZK} / \mathrm{EUR})$ in 2013. However, this practice was interrupted when the exchange rate commitment was introduced in November 2013 as an unconventional policy instrument at the ELB. The CNB resumed publication of the exchange rate path in February 2018. 
B5. Does the central bank regularly publish forecast densities (fan charts) to communicate forecast uncertainty?

Perfect score requires: The central bank should publish forecast densities for inflation, GDP growth, the endogenous interest rate path, the output gap, and the exchange rate.

CNB Score: 0.6/1

Details: The CNB published the fan charts for inflation, GDP growth, and the endogenous interest rate. It did not, however, publish the fan charts of the exchange rate and the output gap. Hence, it did not secure a full score.

https://www.cnb.cz/en/monetary_policy/forecast/

CNB comments: There is no plan to publish forecast densities for the output gap.

However, publication of the exchange rate path was resumed in the form of a fan chart in Februrary 2018. 
B6. Is the underlying methodology of constructing the forecast densities (fan charts) clear and easily accessible?

Perfect score requires: The central bank should publish the forecast densities (fan charts) in all its monetary policy reports, with the methodology clearly explained and/or links to a technical paper is provided.

CNB Score: 0/1

Details: The CNB did not explain the underlying methodology for constructing the fan charts in each Inflation Report. It had confined that to brief notes associated with each chart.

CNB comments: The methodology was explained in a box when fan charts were being introduced. There is no plan to publish it in every Inflation Report, the brief notes associated with each chart are deemed sufficient. 


\begin{abstract}
B7. Does the central bank regularly publish an assessment of forecast revisions (decomposition of forecast changes vis-à-vis the previous forecast)?

Perfect score requires: The central bank should publish an assessment of forecast revisions for inflation, GDP growth, the endogenous interest rate, the output gap, and the exchange rate, with a discussion of the underlying causes of the forecast revisions.
\end{abstract}

CNB Score: $0.6 / 1$

Details: Each published CNB Inflation Report in 2017 included a section entitled, "Comparison with the previous forecast", which provides a discussion of the underlying causes behind the forecast revisions (see the link below). No revisions for the exchange rate or the output gap forecasts were published, though.

http://www.cnb.cz/miranda2/export/sites/www.cnb.cz/en/monetary policy/inflation_report s/2017/2017_III/download/ir_III 2017.pdf

CNB comments: The assessment of changes in the exchange rate forecast was reintroduced together with its resumed publication in February 2018. The CNB also resumed publishing a chart that breaks down the changes of the interest rate path to the contributions of its individual fundamental factors. However, there is no plan to introduce an assessment of changes in the output gap forecast, as it plays no direct role in the CNB's core forecasting model. 


\section{B8. Does the central bank publish alternative scenarios in their monetary policy reports to illustrate key risk(s) to the baseline forecast? \\ Perfect score requires: The central bank should publish the alternative scenario(s) to communicate key risk(s) to the baseline forecast.}

\section{CNB Score: 0/1}

Details: The CNB did not regularly publish the alternative scenario(s) in the first 3 Inflation Reports in 2017. In the last Inflation Report of 2017 there was a sensitivity scenario discussing the possible impact of higher domestic inflation pressures.

CNB comments: The CNB occasionally publishes alternative scenarios or sensitivity analyses, if there is a key risk identified during the forecasting process and the Board asks for a scenario at a regular meeting with the staff held during the forecasting rounds. Some scenarios may be produced for internal purposes, though, without being published. This was, particularly, common during the exchange rate commitment period and immediately after the exit. 
B9. Do the monetary policy reports include historical and forecasts for financial variables? Financial variables include long-term government bond yields, consumer lending rates, mortgage rates, equity prices, property prices, credit aggregates, corporate risky spreads (e.g., BAA-AAA bond yields), and credit standards (e.g., loan officer surveys). All data should be available in downloadable format.

Perfect score requires: The central bank should publish historical data on 5 or more of the above variables are available, and forecasts for 5 or more of the above variables are available.

CNB Score: $0.5 / 1$

Details: The CNB published historical data on the government bond yield curve, consumer lending rates, mortgages rates, property prices, and credit standards (loan office surveys). 
C1. Does the central bank publish a press statement immediately following the policy decisions?

Perfect score requires: The central bank should publish a press statement immediately after each policy decision in English.

CNB Score: $1 / 1$

Details: The CNB published statements after each policy decision in both Czech and English (see the link below).

https://www.cnb.cz/en/monetary policy/bank board minutes/index.html 
C2. Is the policy decision explained at a press conference immediately after it is announced? Are the presentations available in English?

Perfect score requires: Following every policy meeting, and at pre-announced dates and times, the central bank holds a press conference. The press conference as well as the $Q \& A$ session is webcasted and made available on the central bank's website. Moreover, the presentations are available in downloadable form in English.

CNB Score: $1 / 1$

Details: Following every policy meeting, and at pre-announced dates and times, the CNB held press conferences. The press conference as well as the Q\&A sessions were webcasted and were made available. (See the link below).

http://www.cnb.cz/cs/verejnost/pro_media/audio video/2017/

Presentations in both Czech and English were available (see the link below). http://www.cnb.cz/en/public/media_service/audio_video/2017/index.html

CNB comments: Producing a transcript of the Governor's remarks in English may be considered in the future. 
C3. Does the central bank present its regular forecast updates with the $Q \& A$ session to journalists, analysts, and market participants? Are the presentations available in English?

Perfect score requires: The central bank presents its regular forecast updates with the Q\&A session to journalists, analysts and market participants. Moreover, the central bank publishes presentations in English.

CNB Score: $1 / 1$

Details: The CNB presented its regular forecast updates to journalists, analysts, and market participants. The audience was given the opportunity to ask questions and provide comments. Moreover, the central bank published presentations in English. The CNB made the videos available on the website (see the link below).

http://www.cnb.cz/soubory_ke_stazeni/multimedia/2017/20170804_setkani_s_analytiky_I II 2017 hd.mp4 


\begin{abstract}
C4. Is there a public account of the policy deliberations ("minutes") published in less than one month after the meeting?

Perfect score requires: If policy decisions are made by a monetary policy committee, the central bank should publish detailed minutes with the voting outcomes on the main policy instrument. Moreover, the contributions and votes of the individual monetary policy committee members are clearly attributed. If policy decisions are made by a single policymaker, clear arguments and explanations are expected from the central bank.
\end{abstract}

CNB Score: $0.75 / 1$

Details: The CNB provided detailed "minutes" with voting results on the main policy instrument attributed to the MPC members. While the voting results on the main policy instrument were presented separately in an Excel file, the contributions by individual MPC members were not recorded (see the link below). http://www.cnb.cz/en/monetary_policy/bank_board_minutes/

Recommendations: We would like to highlight the case of the Riksbank which published a separate document ("Monetary policy minutes"), which contained a full account of the discussions and the contribution of each MPC member during the meeting (see the link below).

http://www.riksbank.se/Documents/Protokoll/Penningpolitiskt/2017/pro penningpolitiskt 170906 eng.pdf

CNB Comment: The CNB plans to have a discussion with the Board during the first half of 2018 about switching to fully-attributed minutes of MPC meetings. 


\section{C5. Is the role of staff and policymakers in the baseline forecast process communicated clearly? \\ Perfect score requires: The ownership of the forecast, and the role of the staff versus the policymakers in the baseline forecast process are defined clearly.}

\section{CNB Score: $1 / 1$}

Details: The ownership of the forecast and the role of the staff and the policymakers in the decision-making process were defined clearly.

In the foreword of each Inflation Report published in 2017, the CNB states clearly that: "The forecast is the key, but not the only, input to our monetary policy decision-making. Unless the economic situation requires an extraordinary monetary policy meeting, the Bank Board meets eight times a year to discuss monetary policy issues. At four of the meetings (in February, May, August and November) we discuss a new forecast, while at the other four (in March, June, September and December) we discuss the risks and uncertainties of the most recent forecast in the light of newly available information on domestic and foreign economic developments. Due to the arrival of new information since the forecast was drawn up and to the possibility of the Bank Board members assessing its risks differently, the decision we adopt may not fullycorrespond to the message of the forecast prepared by our experts." 
C6. Is the forecasting performance of the central bank reviewed at least once a year in the monetary policy reports or in a separate document?

Perfect score requires: The central bank reviews its forecasting perfrmance at least once a year.

CNB Score: $1 / 1$

Details: The CNB reviewed its forecasting performance in every Inflation Report and Annual Report. 
C7. When was the last time the central bank or the government held or invited an external evaluation of the policy framework and the FPAS, and made the results publicly available?

Perfect score requires: There is an external and independent evaluation of the policy framework and the FPAS within the last five years. The results are publicly available.

CNB Score: 0/1

Details: There has been no external or independent evaluation of the policy framework or FPAS held at the CNB.

CNB comments: Staff from the CNB mentioned that the bank may consider asking the IMF to do an external evaluation in the future, after switching to its planned extended core model. 


\section{REFERENCES}

Adrian, T., F. Duarte, F. Grinberg, and T. Mancini-Griffoli, 2018, "Monetary Policy and Financial Conditions: A Cross-Country Study," Chapter 7 of Advancing the Frontier of Monetary Policy Making, edited by T. Adrian, D. Laxton, and M. Obstfeld, (Washington, DC.: International Monetary Fund).

Adrian, T., D. Laxton and M. Obstfeld, 2018, Advancing the Frontier of Monetary Policy Making (Washington, DC.: International Monetary Fund).

Alichi, A., J. Benes, J. Felman, I. Feng, C. Freedman, D. Laxton, E. Tanner, D. Vavra, and H. Wang, 2015a, "Frontiers of Monetary Policymaking: Adding the Exchange Rate as a Tool to Combat Deflationary Risks in the Czech Republic," IMF Working Paper No. 15/74 (Washington, DC.: International Monetary Fund).

Alichi, A., C. Freedman, K. Clinton, D. Laxton, M. Juilliard, J. Turunen, and H. Wang, 2015b, "Avoiding Dark Corners: A Robust Monetary Policy Framework for the United States," IMF Working Paper No. 15/134 (Washington, DC.: International Monetary Fund).

Al-Mashat, R., K. Clinton, D. Laxton and H. Wang, 2018a, "Czech Republic: Transition to the Frontier," Chapter 10 of Advancing the Frontier of Monetary Policy Making, edited by T. Adrian, D. Laxton, and M. Obstfeld, (Washington, DC.: International Monetary Fund).

Al-Mashat, R., K. Clinton, D. Laxton and H. Wang, 2018b, "United States: Federal Reserve's Dual Mandate," Chapter 7 of Advancing the Frontier of Monetary Policy Making, edited by T. Adrian, D. Laxton, and M. Obstfeld, (Washington, DC.: International Monetary Fund).

Andrle Michal, Hlédik Tibor, Kameník Ondra and Vlček Jan, 2009, "Implementing the New Structural Model of the Czech National Bank", (Prague, Czech Republic: Czech National Bank).

Benes, J., K. Clinton, M. Johnson, D. Laxton, and T. Matheson, 2010, "Structural Models in Real Time,” IMF Working Paper No. 10.56 (Washington, DC.: International Monetary Fund).

Benes, J., M. Kumhof, and D. Laxton, 2014a, Financial Crises in DSGE Models: Selected Applications of MAPMOD, IMF Working Paper No. 56, available at http://www.imf.org/external/pubs/cat/longres.aspx?sk=41466.0 
Benes, J. M. Kumhof, and D. Laxton, 2014b, Financial Crises in DSGE Models: A Prototype Model, IMF Working Paper No. 57, available at, http://www.imf.org/external/pubs/cat/longres.aspx?sk=41467.0

Benes, J. D. Laxton, and J. Mongardini, 2016, "Mitigating the Deadly Embrace in Financial Cycles: Countercyclical Buffers and Loan-to-Value Limits, April, IMF Working Paper 16/87.

Carabenciov, I., C. Freedman, R. Garcia-Saltos, O. Kamenik, D. Laxton and P. Manchev. 2013, "GPM6: The Global Projection Model with 6 Regions," IMF Working Paper No. 13/87 (Washington, DC.: International Monetary Fund).

Clinton, K., C. Freedman, M. Juillard, O. Kameník, D. Laxton, and H. Wang, 2015, "Inflation-Forecast Targeting: Applying the Principle of Transparency," IMF Working Paper No. 15/132 (Washington, DC.: International Monetary Fund).

Clinton, K., T. Hlédik, T. Holub, D. Laxton, and H. Wang, 2017, “Czech Magic: Implementing Inflation-Forecast Targeting at the CNB," IMF Working Paper No. 17/21 (Washington, DC.: International Monetary Fund).

Clinton, K., M. Johnson, O. Kamenik and D. Laxton, 2010, "International Deflation Risks Under Alternative Macroeconomic Policies,” Journal of Japanese and International Economies available at www.sciencedirect.com

Coats, W., D. Laxton and D. Rose, 2003, The Czech National Banks Forecasting and Policy Analysis System, (Prague, Czech Republic: Czech National Bank).

Dincer, N. N., and B. Eichengreen., 2014., "Central Bank Transparency and Independence: Updates and New Measures.," International Journal of Central Banking, Vol. 10, No. (1), March.

Franta, M., T. Holub, P. Král, I. Kubicová, K. Šmídková, and B. Vašíček, 2014, "The Exchange Rate as an Instrument at Zero Interest Rates: The Case of the Czech Republic," Research and Policy Notes 3, Czech National Bank.

Freedman, C. and D. Laxton, 2009a, "Why Inflation Targeting?” IMF Working Paper No. 09/86 (Washington, DC.: International Monetary Fund).

_ 2009b, “IT Framework Design Parameters,” IMF Working Paper No. 09/87 (Washington, DC: International Monetary Fund).

_ 2009c, "Inflation Targeting Pillars: Transparency and Accountability," IMF Working Paper 09/262 (Washington, DC: International Monetary Fund). 
Goretti, M., and D. Laxton, 2005, "Long-Term Inflation Expectations and Credibility," Box 4.2 in Chapter 4 of the September 2005 World Economic Outlook, International Monetary Fund.

Holub, T. and J. Hurník, 2008, “Ten Years of Czech Inflation Targeting: Missed Targets and Anchored Expectations. Emerging Markets Finance and Trade, Vol. 44, No. 6 (November/ December), pp. 67-86.

Naudon, A. and A. Pérez, 2017, “An Overview of Inflation-Targeting Frameworks: Institutional Arrangements, Decision-making, \& the Communication of Monetary Policy," Working Paper 811, Santiago, Banco Central de Chile. available at http://si2.bcentral.cl/public/pdf/documentos-trabajo/pdf/dtbc811.pdf.

Obstfeld, M., K. Clinton, O. Kamenik, D. Laxton, Y. Ustyugova, and H. Wang, 2016, "How to Improve Inflation Targeting in Canada," IMF Working Paper No. 16/192.

Šmídková, ed., 2008, "Evaluation of the fulfilment of the CNB's inflation targets 19982007,” Prague, Czech National Bank.

Šmíková, K. and A. Bulíř, 2007, "Striving to Be 'Clearly Open' and 'Crystal Clear': Monetary Policy Communication of the CNB," Czech Journal of Economics and Finance, Vol. 57, No. 11-12.

Svensson, L. E. O., 1997, “Inflation Forecast Targeting: Implementing and Monitoring Inflation Targets," European Economic Review, Vol. 41.

_ 2007, "Monetary Policy and the Interest Rate Path," speech presented at Danske Bank, Stockholm, August 22, available at www.riksbank. se/templates/Page.aspx?id=25561. 